\title{
Phosphorylation of Tip60 by p38a regulates p53-mediated PUMA induction and apoptosis in response to DNA damage
}

\author{
Yingxi $\mathrm{Xu}^{1,2}$, Rong Liao ${ }^{2}$, Na $\mathrm{Li}^{1}$, Rong Xiang ${ }^{1}$, Peiqing Sun ${ }^{2}$ \\ ${ }^{1}$ College of Medicine, Nankai University, Tianjin, P.R. China, 300071 \\ ${ }^{2}$ Departments of Cell and Molecular Biology, The Scripps Research Institute, La Jolla, CA 92037 \\ Correspondence to: \\ Peiqing Sun, e-mail: pqsun@scripps.edu \\ Rong Xiang, e-mail: rxiang@nankai.edu.cn \\ Keywords: p38, Tip60, p53, PUMA, apoptosis \\ Received: September 16,2014 Accepted: November 08, $2014 \quad$ Published: December 10, 2014
}

\section{ABSTRACT}

Tip60 is a multifunctional acetyltransferase involved in multiple cellular functions. Acetylation of p53 at K120 by Tip60 promotes p53-mediated apoptosis after DNA damage. We previous showed that Tip60 activity is induced by phosphorylation at T158 by $\mathrm{p} 38$. In this study, we investigated the role of p38-mediated Tip60 phosphorylation in p53-mediated, DNA damage-induced apoptosis. We found that DNA damage induces p38 activation, Tip60-T158 phosphorylation, and p53-K120 acetylation with similar kinetics. p38a is essential for DNA damage-induced Tip60-T158 phosphorylation. In addition, both p38a and Tip60 are essential for p53-K120 acetylation, binding of p53 to PUMA promoter, PUMA expression and apoptosis induced by DNA damage. Moreover, DNA damage induces protein kinase activity of p38a towards Tip60-T158, and constitutive activation of p38 in cells leads to increases in Tip60-T158 phosphorylation, p53-K120 acetylation, PUMA expression and apoptosis. Furthermore, the Tip60-T158A mutant that cannot be phosphorylated by $\mathrm{p} 38$ fails to mediate p53-K120 acetylation, PUMA induction, and apoptosis following DNA damage. These results establish that Tip60-T158 phosphorylation by p38 plays an essential role in stimulating Tip60 activity required for inducing the p53-PUMA pathway that ultimately leads to apoptosis in response to DNA damage, which provides a mechanistic basis for the tumor-suppressing function of p38 and Tip60.

\section{INTRODUCTION}

Both chemotherapy and radiotherapy can induce DNA damage in rapidly dividing cancer cells, which triggers cell cycle arrest and apoptosis by promoting activation of the p53 signaling pathway. Activated p53 mediates reversible cell cycle arrest through transcriptional induction of $\mathrm{p} 21^{\mathrm{WAF} 1}$, thus allowing time for the repair of damaged DNA and subsequent resumption of cell proliferation upon the completion of DNA repair [1-2]. On the other hand, cells that are unable to repair damaged DNA undergo apoptosis, a process that is also mediated by p53. Upon posttranslational modification, p53 mediates apoptosis by inducing the transcription of PUMA [3-4]. PUMA is a pro-apoptosis member of the BH3-only subgroup of the Bcl-2 family [5], whose proapoptotic activity requires the interactions with other
Bcl-2 family members and mitochondria localization [6]. PUMA could bind to Bcl-2, induce the activation of multi domain proapoptotic protein Bax and/or Bak, localize to the mitochondria to induce cytochrome $\mathrm{c}$ release, and trigger mitochondria dysfunction and caspase activation, thereby activating the rapid induction of programmed cell death [7].

The mechanism by which p53 transactivates different sets of target genes to result in either cellcycle arrest or apoptosis is not well understood. The transcriptional activity of p53 is regulated by various posttranslational modifications [8], which might impact the decisions of cell fate. In addition to phosphorylation, p53 is acetylated in response to DNA damage, and the level of acetylation contributes to p53 activation [9-11]. p53 can be acetylated by the histone acetyltransferase $\mathrm{CBP} / \mathrm{p} 300$ and p300/CBP associated factor (PCAF) 
at $\mathrm{K} 320$ [10, 12], K164 [13] or C-terminal domain (K370, 372, 373 and K382) [11], which blocks Mdm2 and $\mathrm{Mdmx}$ binding to $\mathrm{p} 53$, thus preventing degradation of p53 and promoting the recruitment of p53 to target promoters. In addition, p53 can be acetylated at K120 by acetyltransferase hMOF and Tip60, which can induce the proapoptotic activity of $\mathrm{p} 53$, but has no effect on the ability of p53 to mediate cell cycle arrest [14].

Tip60 is a member of the MYST family of histone acetyltransferases (HATs), which has been indicated in several cellular processes [15-16]. Tip60 can act as a transcriptional coactivator after being recruited to target promoters and enhance transactivation of target genes through acetylation of histones. Furthermore, Tip60 can modify the activity or expression of non-histone substrates through direct interaction and acetylation in a transcription-independent mechanism [14-16]. Tip60 has been shown to participate in apoptosis [17-18], DNA damage responses [19], and oncogene-induced senescence [20], and is a potential tumor suppressor [21]. Despite the critical function of Tip60 in several cellular processes, the upstream signaling pathways that regulate theTip60 acetyltransferase activity have been poorly studied. We previously showed that in response to activation of the ras oncogene, p38 $\alpha$ phosphorylates Tip60 at T158 to induce its acetyltransferase activity and function in oncogenic ras-induced senescence [20]. This finding prompted us to investigate whether p38-mediated phosphorylation of Tip60-T158, which activates the acetyltransferase activity of Tip60, also contributes to other biological functions of Tip60, such as DNA damage-induced apoptosis. In the current study, we found that DNA damage induces Tip60-T158 phosphorylation in a p38 $\alpha$-dependent manner. Both p38 $\alpha$ and Tip60 are required for DNA damage-induced p53 acetylation at K120, and subsequent binding to p53 to the PUMA promoter and transactivation of PUMA gene expression, and are essential for DNA damageinduced apoptosis. Moreover, DNA damage induces the protein kinase activity of p38 towards Tip60, and constitutive activation of p38 in cells leads to increases in Tip60-T158 phosphorylation, p53-K120 acetylation, PUMA expression and apoptosis. Furthermore, whereas wild type murine Tip60 restored DNA damage-induced p53-K120 acetylation, PUMA expression and apoptosis in cells expressing human specific Tip60 shRNA, the mouse Tip60 mutant that cannot be phosphorylated by p38 (T158A) failed to do so. These results demonstrate that p38-mediated Tip60-T158 phosphorylation contributes to the ability of Tip60 to mediate p53 acetylation and activation, PUMA expression and apoptosis induction in response to DNA damage. These findings have established an essential role of the p38-Tip60-p53-PUMA pathway in DNA damage triggered apoptosis.

\section{RESULTS}

\section{Tip60 is phosphorylated at $\mathrm{T158}$ with same kinetics as $\mathrm{p38}$ activation in response to DNA damage}

To investigate the involvement of p38-mediated Tip60 phosphorylation during DNA damage, U2OS cells were first treated with Doxorubicin (Dox), a chemotherapeutic drug that induces DNA double-strand breaks [22]. Dox treatment induced both activating phosphorylation of p38 and phosphorylation of Tip60 at T158 with similar kinetics in a time-dependent (over a duration from 12 to 60 hours at $1 \mu \mathrm{M}$ ) and dose-dependent (with concentrations ranging from 0.5 to $10 \mu \mathrm{M}$ ) manner (Figure $1 \mathrm{~A}$ and $1 \mathrm{~B}$ ).

Given the ability of Tip60 to acetylate p53 at K120 [14, 23-24], we analyzed changes in the expression of p53 acetylated at K120 (Ace-K120-p53) after Dox treatment. As expected, expression levels of Ace-K120-p53 increased after treatment with Dox, with the same kinetics as the induction of p38 phosphorylation and Tip60 phosphorylation (Figure 1A and 1B).

Furthermore, consistent with the induction of $\mathrm{p} 21^{\mathrm{WAF} 1}$ [2] and PUMA [18] by activated p53 following DNA damage, the expression of $\mathrm{p} 21^{\mathrm{WAF} 1}$ and PUMA were increased in a time-dependent manner after Dox treatment (Figure 1C). However, in the dose-depended test, the induction of $\mathrm{p} 21^{\mathrm{WAF} 1}$ and PUMA was maximal at $1 \mu \mathrm{M}$ of Dox, followed by a sharp decrease at concentrations of $3 \mu \mathrm{M}$ and above (Figure 1D). The reduction in $\mathrm{p} 21^{\mathrm{WAF} 1}$ and PUMA expression by high concentrations of Dox was reported before [1, 25-26]. However, the mechanism behind this observation is unclear. One possible explanation is that high Dox concentrations induce strong apoptosis leading to selection against high $\mathrm{p} 21^{\mathrm{WAF} 1}$ - and PUMA-expressers in the cell populations subjected to analysis. Alternatively, high Dox concentrations may induce p53-independent mechanisms that inhibit the expression of $\mathrm{p} 21^{\mathrm{WAF} 1}$ and PUMA. We had thus performed further analyses using $1 \mu \mathrm{M}$ of Dox.

\section{p38a is required for phosphorylation of Tip60 at T158, Tip60-mediated acetylation of p53 at $\mathrm{K} 120$, and $\mathrm{p53}$-mediated induction of $\mathrm{p} 21^{\mathrm{WAF} 1}$ and PUMA following DNA damage}

The finding that p38 activation, Tip60-T158 phosphorylation, and p53-K120 acetylation are induced with similar kinetics after DNA damage (Figure 1) suggests that p38 may phosphorylate Tip60 at T158, leading to activation of Tip60 that in turn acetylates p53 at K120. To determine whether p38 is responsible for Tip60 phosphorylation and activation, we examined the effect of p38 knockdown in U2OS cells during Dox-or $\gamma$ radiation-induced DNA damage. 


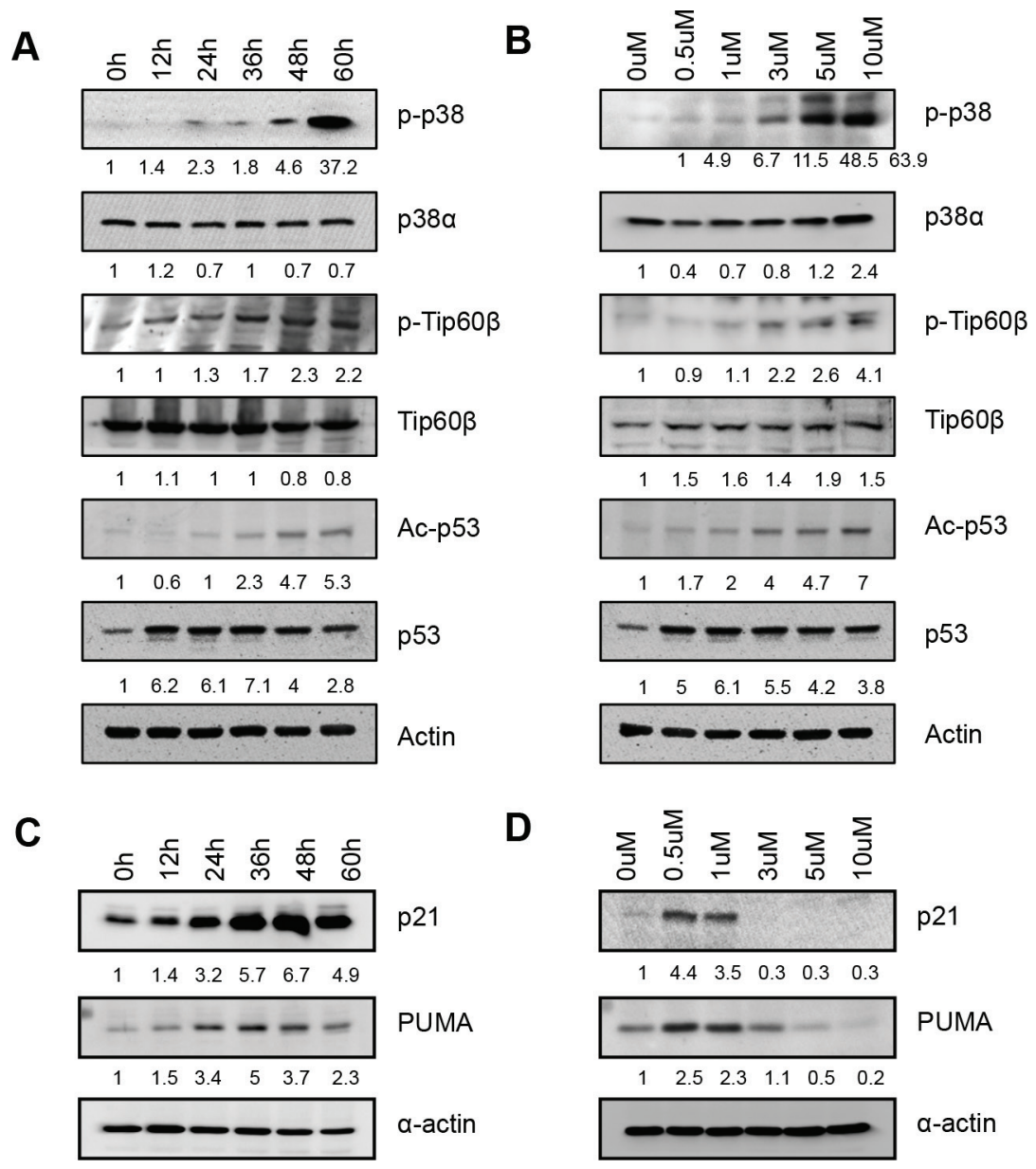

Figure 1: p38 activation, Tip60-T158 phosphorylation, and p53-K120 acetylation are induced with same kinetics by DNA damage. (A) Weston blot analysis of U2OS cells treated with $1 \mu \mathrm{M}$ of Dox for indicated durations, detecting p38a, p-p38, p-Tip60-T158, Tip60, ac-p53-K120, p53 and actin. (B) Weston blot analysis of U2OS cells treated with indicated concentrations of Dox for $24 \mathrm{~h}$, detecting p38 $\alpha$, p-p38, p-Tip60-T158, Tip60, ac-p53-K120, p53 and actin. (C) Weston blot analysis of U2OS cells treated with $1 \mu \mathrm{M}$ Dox for indicated durations, detecting PUMA, p21 and actin. (D) Weston blot analysis of U2OS cells treated with indicated concentrations of Dox for $24 \mathrm{~h}$, detecting PUMA, p21 and actin.

In contrast to the control, GFP shRNA, the p38 $\alpha$ shRNAs

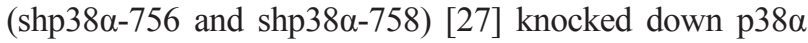
expression, and greatly reduced the induction of Tip60-K158 phosphorylation and p53-K120 acetylation by Dox and $\gamma$-radiation (Figure 2A). Consistent with the ability of p53 to induce PUMA transcription upon acetylation at K120 by Tip60 [14], p38ashRNA also decreased the induction of PUMA protein (Figure 2A) and RNA (Figure 2C and 2D) levels by DNA damage. Furthermore, we examined the effect of a chemical inhibitor of p38, SB203580, which inhibits p38 catalytic activity by binding to the ATPbinding pocket, but does not inhibit phosphorylation of p38 by upstream kinases [28]. We again observed a similar decrease in the induction of Tip60-T158 phosphorylation, p53-K120 acetylation, and PUMA expression by Dox or $\gamma$-radiation in cells treated with SB203580, as compared to the vehicle-treated cells (Fig. 2B and 2E). Taken together, these results indicate that in response to DNA damage, p38a is responsible for the phosphorylation of Tip60-T158, which stimulates the activity of Tip60 leading to acetylation of p53-K120 and induction of PUMA.

It was reported that acetylation of $\mathrm{p} 53-\mathrm{K} 120$ by Tip60 only stimulates the ability of p53 to bind to the PUMA promoter and to induce PUMA expression, but has no effect on the ability of p53 to regulate the p $21^{\text {WAF1 }}$ promoter [14]. However, we observed that the p21 $1^{\mathrm{WAF} 1}$ induction by DNA damage was also reduced modestly at both protein and mRNA levels in cells expressing p38 $\alpha$ shRNA or treated with SB203580 (Figure 2A, 2C, $2 \mathrm{D}$ and $2 \mathrm{E}$ ), although the effect of $\mathrm{p} 38$ inhibition was stronger on PUMA than on $\mathrm{p} 21^{\mathrm{WAF} 1}$. This indicates that p38 may also activate an additional, Tip60-independent pathway that stimulates the ability of p53 of induce $\mathrm{p} 21^{\mathrm{WAF} 1}$ during DNA damage. 


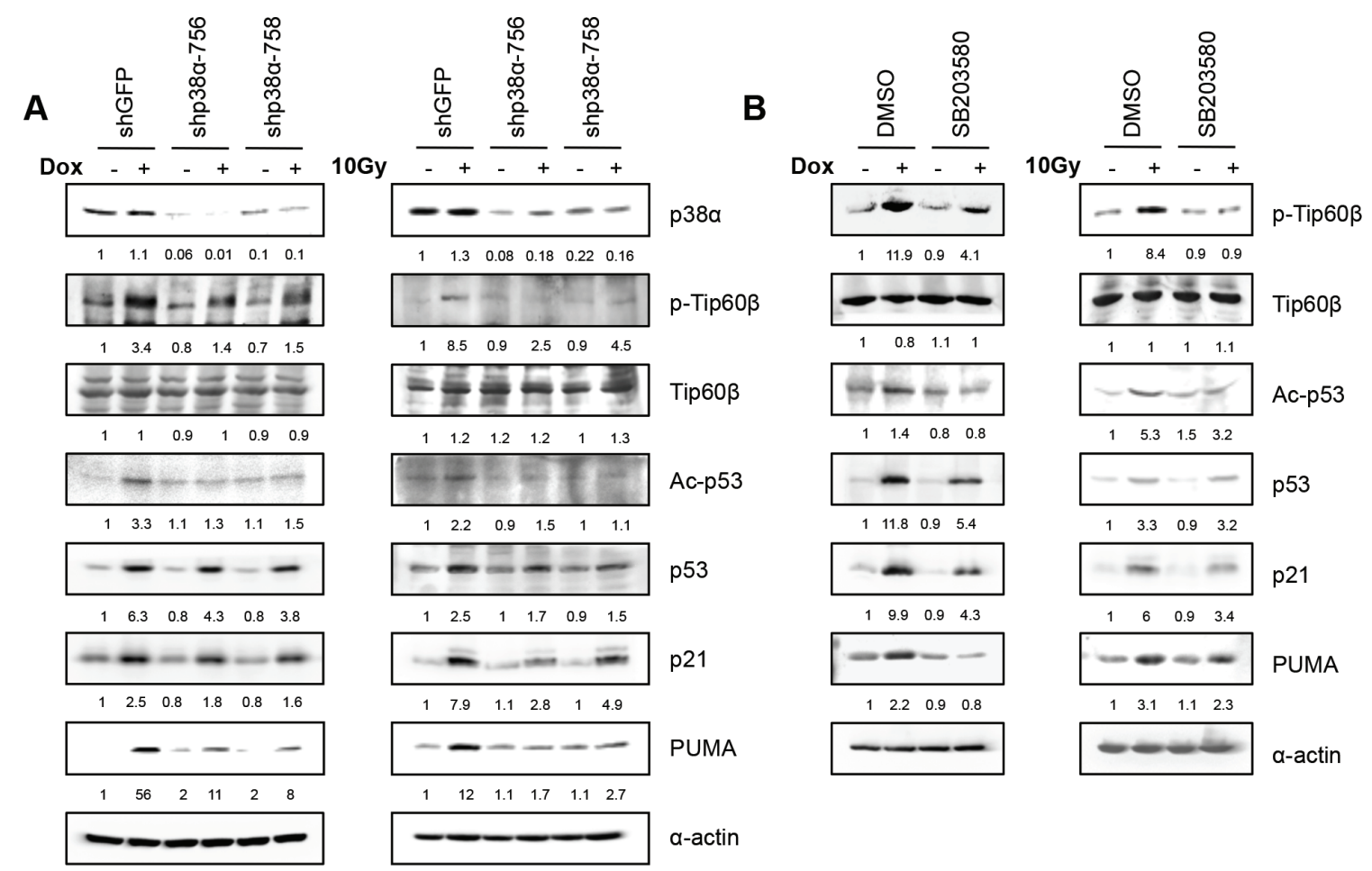

C

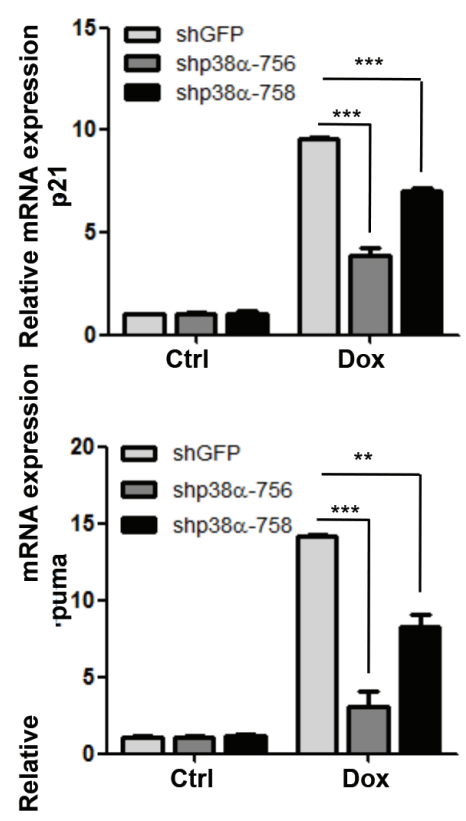

D

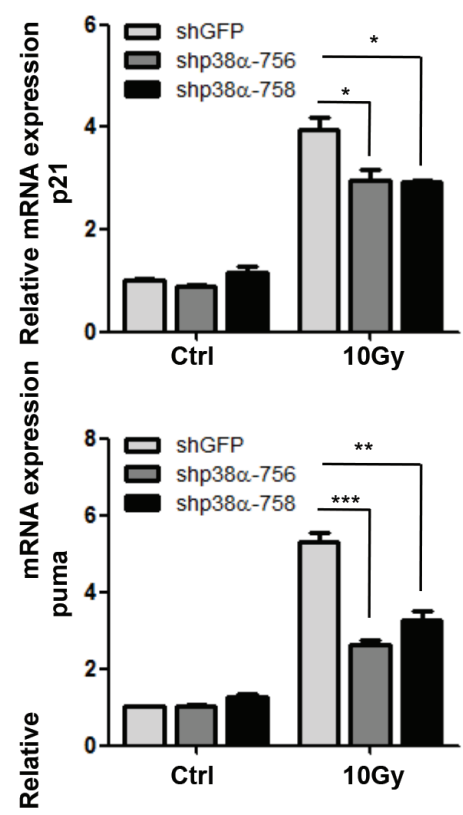

E

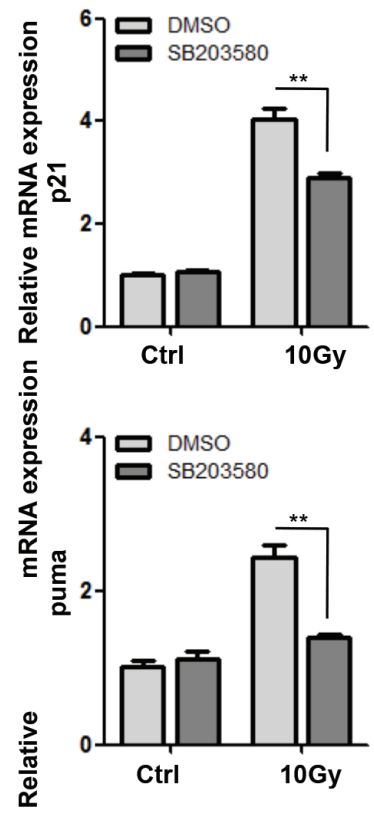

Figure 2: p38a is required for the induction of Tip60-T158 phosphorylation, p53-K120 acetylation and p21 ${ }^{\mathrm{WAF} 1}$ and PUMA expression following DNA damage. (A) U2OS cells transduced with shRNA for GFP (shGFP) or p38 $\alpha$ (shp38 $\alpha-756$ or -758) were treated with $1 \mu \mathrm{M}$ of Dox for $36 \mathrm{~h}$ (left panels) or $10 \mathrm{~Gy}$ of $\gamma$-radiation followed by incubation for $72 \mathrm{~h}$ (right panels). Cell lysis was subjected to Western blot analysis detecting the indicated proteins. (B) U2OS cells were pre-treated with $10 \mu \mathrm{M}$ of the p38 inhibitor SB203580 or DMSO for $1 \mathrm{~h}$, and then treated in the presence of SB203580 or DMSO with $1 \mu \mathrm{M}$ of Dox for $36 \mathrm{~h}$ (left panels) or 10 Gy of $\gamma$-radiation followed by incubation for $72 \mathrm{~h}$ (right panels). Cell lysis was subjected to Western blot analysis detecting the indicated proteins. (C-D) U2OS cells transduced with shRNA for GFP (shGFP) or p38 $\alpha$ (shp38 $\alpha-756$ or -758) were treated with $1 \mu \mathrm{M}$ of Dox for $36 \mathrm{~h}$ (C) or 10 Gy of $\gamma$-radiation followed by incubation for $72 \mathrm{~h}$ (D) mRNA levels of PUMA (lower panels) and p2 $1^{\text {wAF1 }}$ (upper panels) were detected by real-time PCR. Values are mean \pm SEM for triplicates. (E) U2OS cells were pre-treated with $10 \mu \mathrm{M}$ of the p38 inhibitor SB203580 or DMSO for $1 \mathrm{~h}$, and then treated in the presence of SB203580 or DMSO with $10 \mathrm{~Gy}$ of $\gamma$-radiation followed by incubation for $72 \mathrm{~h}$. mRNA levels of PUMA (lower panel) and p21 $1^{\text {WAFI }}$ (upper panel) were detected by real-time PCR. Values are mean \pm SEM for triplicates. 


\section{Tip60 is required for acetylation of p53 at K120 and induction of PUMA expression, but not induction of $\mathrm{p}^{2} 1^{\mathrm{WAF} 1}$, in response to DNA damage}

To further investigate the role of Tip60 in p53 acetylation and activation, we knocked down Tip60 in U2OS cells using shRNAs we previously published [20]. Consistent with previous reports [14, 29], downregulation of Tip60 by shRNAs (shTip60-887 or shTip60-1506) decreased the acetylation of $\mathrm{p} 53$ at K120 induced by either Dox or $\gamma$-radiation (Figure 3A). Moreover, induction of PUMA expression by DNA damage was decreased at both protein and mRNA levels (Figure 3A, 3B and 3C). Therefore, those findings confirm that Tip60 mediates the acetylation of p53 at K120, which stimulate the p53 activity in inducing a proapoptotic target gene PUMA.

In contrast to the cells expressing $\mathrm{p} 38 \alpha$ shRNAs, neither the mRNA level nor the protein level of p21 ${ }^{\text {WAF1 }}$ changed in cells expressing the Tip60 shRNA (Figure 3A, $3 \mathrm{~B}$ and $3 \mathrm{C}$ ). This confirms that Tip60-mediated acetylation of p53 at K120 only influences the transcription of a p53 target gene PUMA that is involved in apoptosis, but not $\mathrm{p} 21^{\mathrm{WAF} 1}$ that mediates cell-cycle arrest during DNA damage, whereas p38 $\alpha$ regulates the expression of both p53 target genes.

Furthermore, we have confirmed that DNA damageinduced PUMA and $\mathrm{p} 21^{\mathrm{WAF} 1}$ expression is $\mathrm{p} 53$-dependent, as shRNA-mediated knockdown of p53 abrogated the induction of these 2 genes (Figure 3D). This finding is consistent with previously published results [4].

\section{p38 $a$ and Tip60 are required for apoptosis induction in response to DNA damage}

The requirement of $\mathrm{p} 38 \alpha$ in DNA damage-induced Tip60-T158 phosphorylation, p53-K120 acetylation, and PUMA expression raises a possibility that $\mathrm{p} 38 \alpha$ plays an important role in apoptosis induction after DNA damage. We thus analyzed the percentage of Annexin V-positive apoptotic cells by flow cytometry in Dox- and $\gamma$-radiation-treated cells with p38 $\alpha$ knockdown. When incubated with $1 \mu \mathrm{M}$ or $3 \mu \mathrm{M}$ of Dox, approximately $9 \%$ or $12 \%$, respectively, of control cells were apoptotic; $p 38 \alpha$ knockdown reduced the percentage of apoptotic cells to $5 \%$ or $7 \%$, respectively (Figure $4 \mathrm{~A}$ and $4 \mathrm{C}$ ). Similarly, after 10 Gy of $\gamma$-radiation, nearly $8 \%$ of control cells were apoptotic; in cells with p38 $\alpha$ knockdown, the percentage of apoptotic cells dropped to 4\% (Figure 4B and 4D). The p38 inhibitor SB203580 had a similar effect on DNA damage-induced apoptosis. We found that the apoptotic population was decreased in SB203580-treated cells, as compared to the vehicle-treated cells, upon both Dox- and $\gamma$-radiation-induced DNA damage (Figure 4E-4H).

To further investigate the role of the p38-Tip60 pathway in apoptosis induction after DNA damage, we examined the effect of Tip60 knockdown. In cells incubated with $1 \mu \mathrm{M}$ or $3 \mu \mathrm{M}$ of Dox for $24 \mathrm{~h}$, we found that Tip60 knockdown reduced the percentage of apoptotic cells from nearly $8 \%$ to $4 \%$ or from $10 \%$ to $6 \%$, respectively (Figure 5A and 5C). Similarly, the percentage of apoptotic cells induced by 10 Gy of $\gamma$-radiation was also reduced by Tip60 shRNA (Figure 5B and 5D).

Taken together, these results indicate that both p38 $\alpha$ and Tip60 are essential for DNA damage-induced apoptosis, thus implicating a critical function of p38mediated Tip60 phosphorylation in this biological process.

\section{p38 a and Tip60 are essential for DNA damage- induced binding of p53 to the PUMA promoter}

It has been demonstrated that acetylation of p53 by Tip60 stimulates binding of p53 to the PUMA promoter [18]. To examine whether the p38 $\alpha$-Tip60 pathway contributes to the ability of p53 to bind to the PUMA promoter, we tested the effect of $\mathrm{p} 38 \alpha$ and Tip60 knockdown on the $\mathrm{p} 53$ occupancy on the PUMA promoter following DNA damage by ChIP assay. Chromatin DNA associated with p53 was immunoprecipitated from control cells or cells transduced with p38 $\alpha$ or Tip60 shRNA after $\gamma$-radiation, and quantified by real-time PCR using primers amplifying the region from -1342 to -1449 of the PUMA promoter, which encompasses the $\mathrm{p} 53$ binding sites [3]. DNA damage increased binding of p53 to the PUMA promoter; however, the $\gamma$-radiation-induced p53 occupancy on the PUMA promoter was reduced in cells expressing either p38 $\alpha$ shRNA (Figure 6B) or Tip60 shRNA (Figure 6D), as compared to the control cells expressing the GFP shRNA. These results indicate that the p38 $\alpha$-Tip60 pathway regulates the p53 activity in PUMA induction by stimulating p53 binding to the PUMA promoter in response to DNA damage.

We also analyzed the effect of p38 $\alpha$ and Tip60 knockdown on $\mathrm{p} 53$ binding to the $\mathrm{p} 21^{\mathrm{WAF} 1}$ promoter by the ChIP assay, using primers amplifying the $\mathrm{p} 53$ binding sitecontaining region (from -1463 to -1271) of the p21 ${ }^{\text {WAF1 }}$ promoter [30]. Whereas the Tip60 shRNA reduced DNA damage-induced binding of $\mathrm{p} 53$ to the PUMA promoter but not that to the $\mathrm{p} 21^{\mathrm{WAF} 1}$ promoter (Figure 6C and 6D), the $\mathrm{p} 38 \alpha$ shRNA abrogated $\mathrm{p} 53$ binding to both promoters in response to $\gamma$-radiation (Figure 6A and 6B). This again suggests that although Tip60 acetylation is only required for the ability to p53 to bind to and stimulate the transcription from the PUMA promoter, $\mathrm{p} 38 \alpha$ activates another pathway in addition of Tip60-p53-PUMA, which mediates the induction of the $\mathrm{p} 21^{\text {WAF } 1}$ promoter by $\mathrm{p} 53$ upon DNA damage.

\section{Activated p38a directly phosphorylates Tip60-T158 in vitro and induces Tip60-T158 phosphorylation, p53-K120 acetylation, PUMA expression and apoptosis in cells}

To directly assess Tip60 phosphorylation by $\mathrm{p} 38 \alpha$ during DNA damage, we performed in vitro kinase assays 

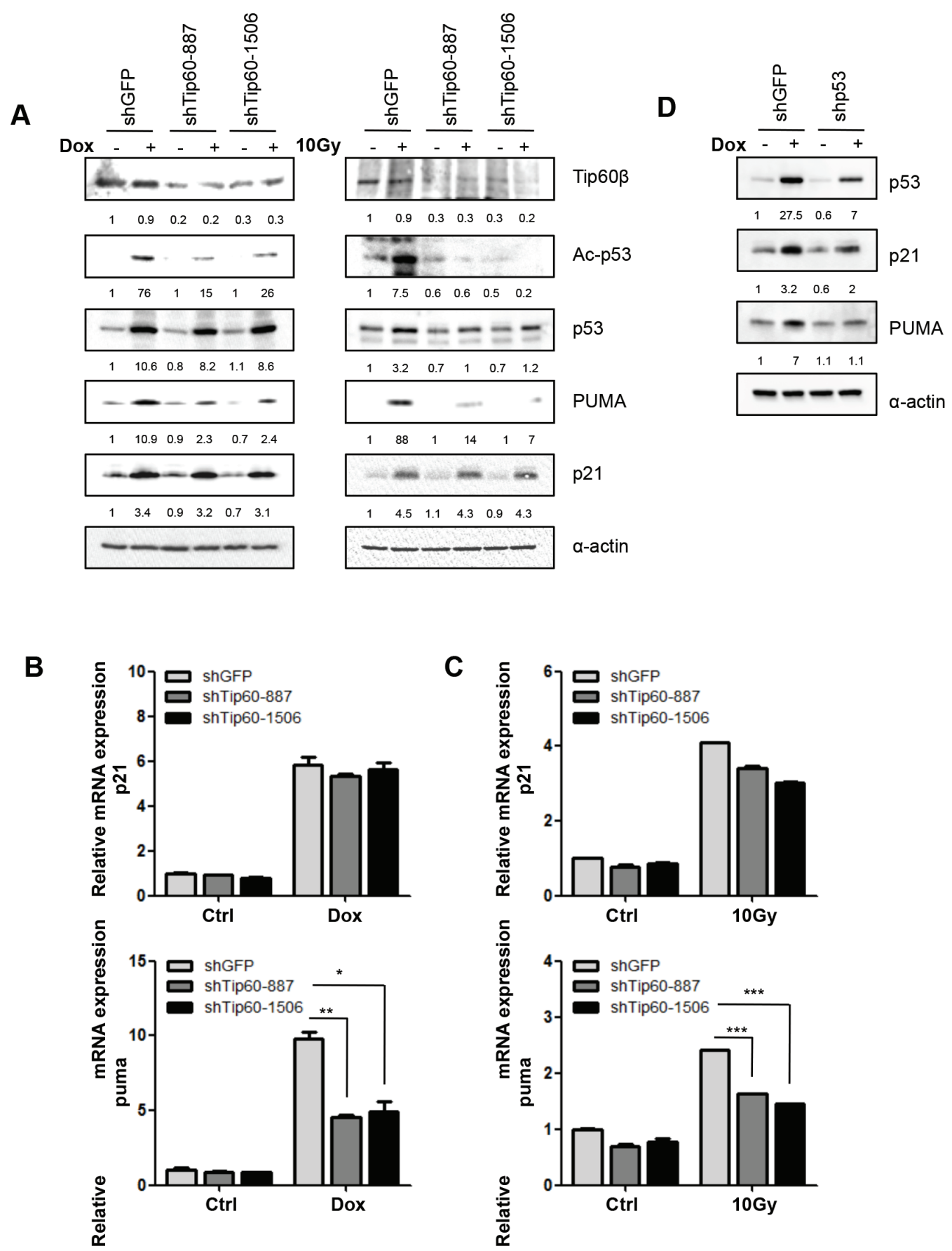

Figure 3: Tip60 is required for acetylation of p53 at K120 and induction of PUMA expression, but not for induction of p21 ${ }^{\text {WAF1 }}$, in response to DNA damage. (A) U2OS cells transduced with shRNA for GFP (shGFP) or Tip60 (shTip60-887 or -1506) were treated with $1 \mu \mathrm{M}$ of Dox for $36 \mathrm{~h}$ (left panels) or $10 \mathrm{~Gy}$ of $\gamma$-radiation followed by incubation for $24 \mathrm{~h}$ (right panels). Cell lysis was subjected to Western blot analysis detecting the indicated proteins. (B-C) U2OS cells transduced with shRNA for GFP (shGFP) or Tip60 (shTip60-887 or -1506) were treated with $1 \mu \mathrm{M}$ of Dox for $36 \mathrm{~h}$ (B) or $10 \mathrm{~Gy}$ of $\gamma$-radiation followed by incubation for $24 \mathrm{~h}$ (C). mRNA levels of PUMA (lower panels) and p2 $1^{\mathrm{WAF} 1}$ (upper panels) were detected by real-time PCR. Values are mean \pm SEM for triplicates. (D) U2OS cells transduced with shRNA for GFP (shGFP) or p53 (shp53) were left untreated (-) or treated with $1 \mu \mathrm{M}$ of Dox for $24 \mathrm{~h}(+)$, and analyzed by Western blotting detecting the indicated proteins.

with immunoprecipitated p38 $\alpha$ using recombinant Tip60 as substrate. After U2OS cells transduced with HA-p38 $\alpha$ were treated with Dox or $\gamma$-radiation, HA-p38 $\alpha$ was immunoprecipitated and incubated with recombinant
Tip60. Tip60 phosphorylation was assessed by Western blotting using the antibody against Tip60pT158. We found that phosphorylation of Tip60-T158 was increased by p38 $\alpha$ isolated from Dox- or $\gamma$-radiation-treated cells 
A

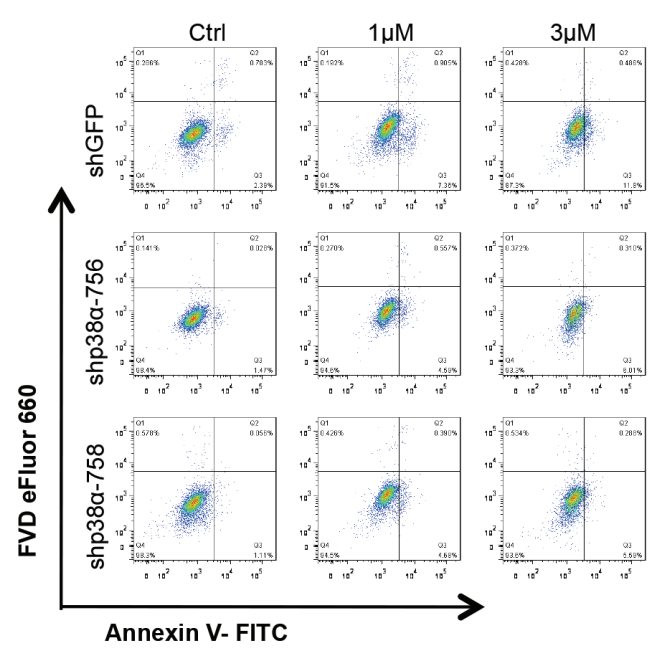

C

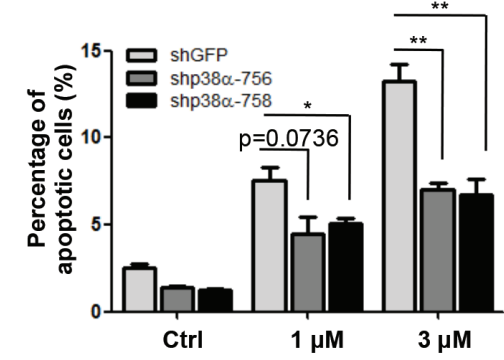

$E$
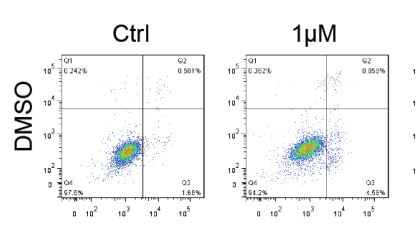

$3 \mu \mathrm{M}$
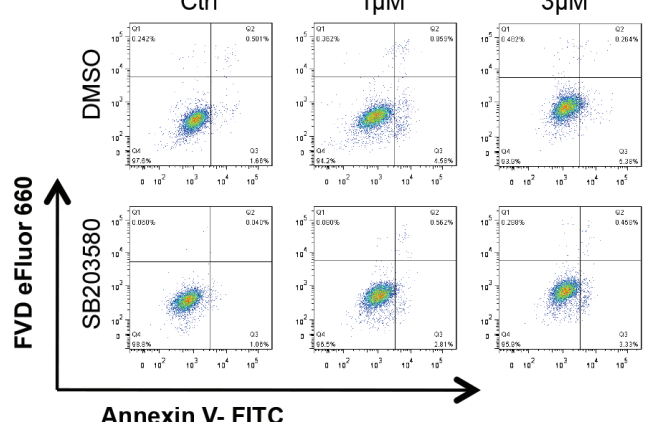

G

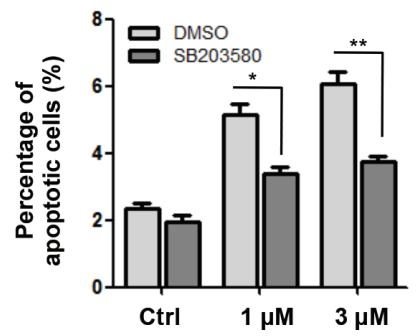

B

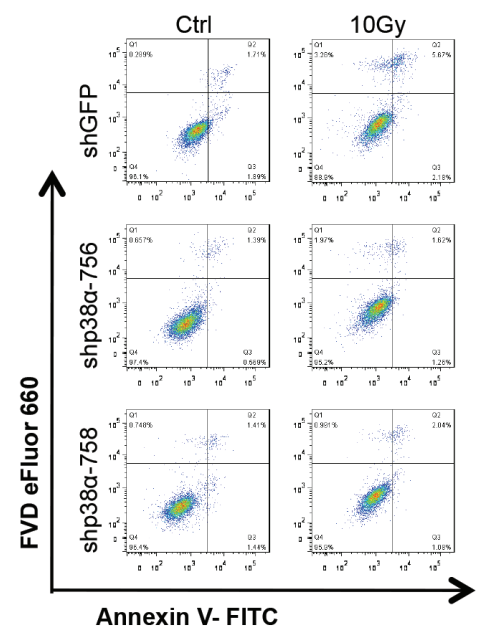

D

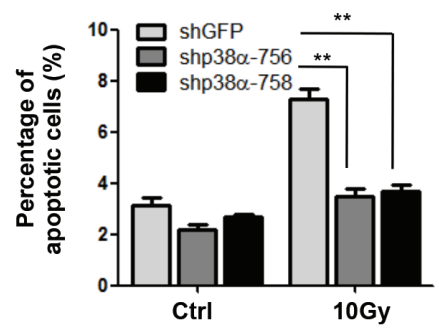

$\mathbf{F}$

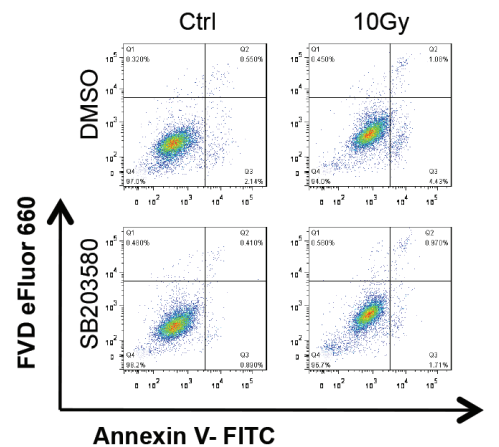

H

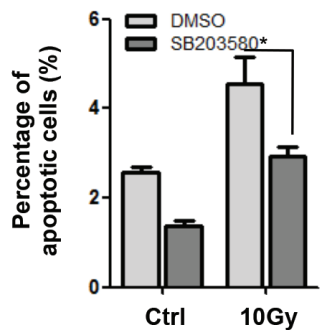

Figure 4: p38a is required for apoptosis induction in response to DNA damage. (A-B) U2OS cells transduced with shRNA

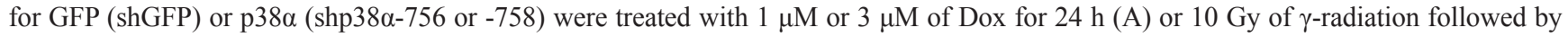
incubation for $24 \mathrm{~h}$ (B). Cells were collected, stained with an FITC-conjugated anti-Annexin-V antibody and FVD eFlour 660 and analyzed by FACS. (C-D) Quantification and statistical analysis of the data in A (C) and B (D). The percentage of apoptotic cells was quantified as the percentage of FITC-positive cells in the gated area. Values are mean \pm SEM for triplicates. (E-F) U2OS cells were pre-treated with the $10 \mu \mathrm{M}$ of p38 inhibitor SB203580 or DMSO for $1 \mathrm{~h}$, and then treated in the presence of SB203580 or DMSO with $1 \mu \mathrm{M}$ or $3 \mu \mathrm{M}$ of Dox for $24 \mathrm{~h}$ (E) or $10 \mathrm{~Gy}$ of $\gamma$-radiation followed by incubation for $24 \mathrm{~h}(\mathrm{~F})$. Cells were collected, stained with an FITC-conjugated anti-Annexin-V antibody and FVD eFlour 660 and analyzed by FACS. (G-H) Quantification and statistical analysis of the data in E (G) or F (H). The percentage of apoptotic cells was quantified as the percentage of FITC-positive cells in the gated area. Values are mean \pm SEM for triplicates. 
A

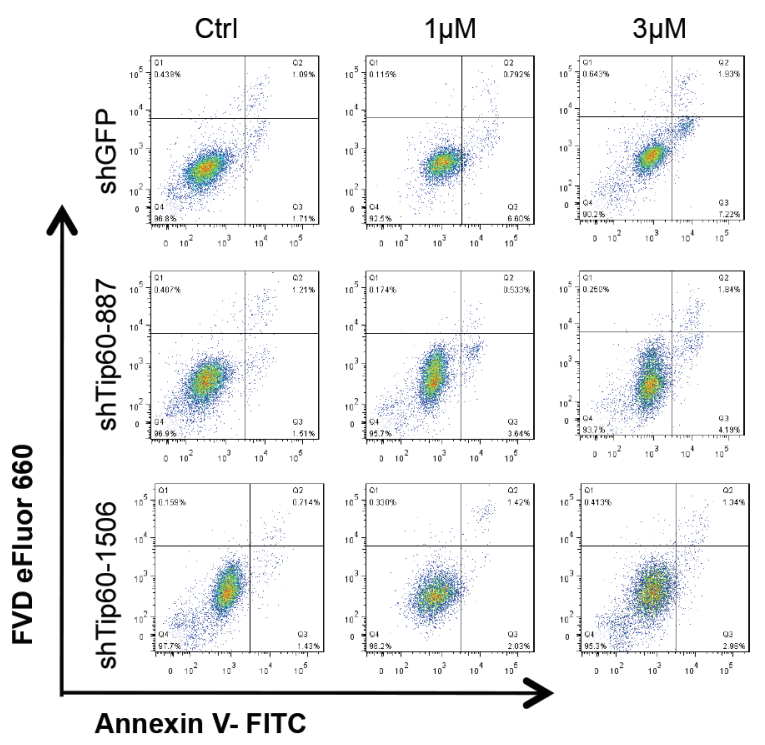

C

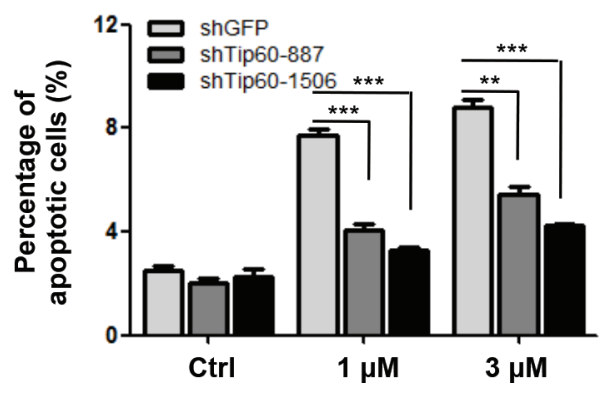

B

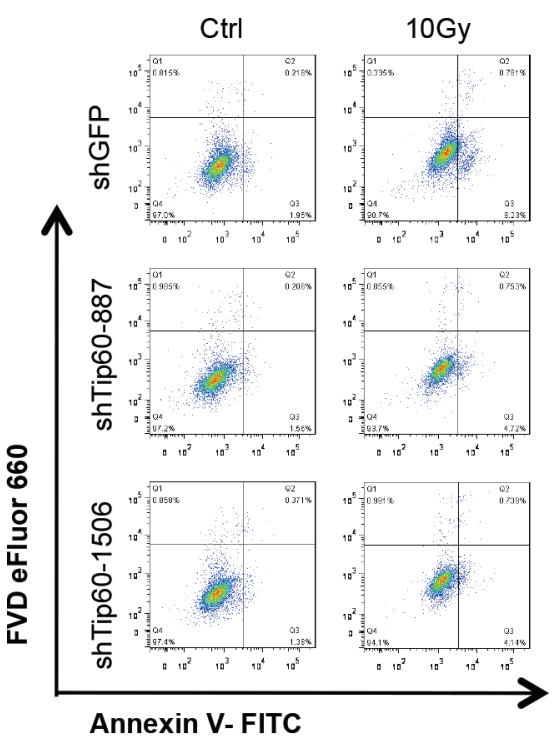

D

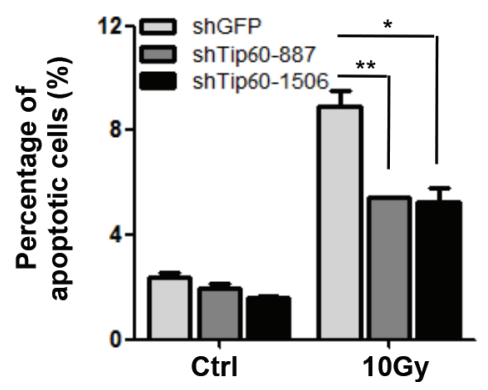

Figure 5: Tip60 is required for apoptosis induction in response to DNA damage. (A-B) U2OS cells transduced with shRNA for GFP (shGFP) or Tip60 (shTip60-887 or -1506) were treated with $1 \mu \mathrm{M}$ or $3 \mu \mathrm{M}$ of Dox for $24 \mathrm{~h}$ (A) or $10 \mathrm{~Gy}$ of $\gamma$-radiation followed by incubation for $24 \mathrm{~h}$ (B). Cells were collected, stained with an FITC-conjugated anti-Annexin-V antibody and FVD eFlour 660 and analyzed by FACS. (C-D) Quantification and statistical analysis of the data in A (C) or B (D). The percentage of apoptotic cells was quantified as the percentage of FITC-positive cells in the gated area. Values are mean \pm SEM for triplicates.

over that from untreated cells (Figure 7A), indicating that DNA damage induces the protein kinase activity of $\mathrm{p} 38 \alpha$ towards Tip60-T158.

We further determined the consequence of constitutive activation of p38 on Tip60, p53, PUMA and apoptosis, using constitutively active mutants of the p38 upstream kinases MKK3 and MKK6 (MKK3E and MKK6E), and a constitutively active mutant of p38 $\alpha$ (p38 $\alpha$ D179A) [27, 31]. Ectopic expression of MKK3E, MKK6E or p38 2 D179A increased activating phosphorylation of $\mathrm{p} 38$, and at the same time, induced Tip60-T158 phosphorylation, p53-K120 acetylation, PUMA expression, whereas the wild type p38 $\alpha$ had no effect (Figure 7B, 7C). MKK3E, MKK6E or p38 $\alpha$ D179A enhanced apoptosis in U2OS cells as compared to the vector controls (Figure 7D, 7E and 7F, 7G).

Therefore, these results indicate that DNA damage induces the protein kinase activity of $\mathrm{p} 38 \alpha$ towards Tip60, and that in cells, activated p38 $\alpha$ mediates Tip60-T158 phosphorylation and subsequent acetylation of p53-K120 by Tip60, leading to p53-mediated apoptosis.

\section{p38 $\beta$ also mediates Tip60-T158 phosphorylation, p53-K120 acetylation, PUMA expression and apoptosis in response to DNA damage}

Interestingly, ectopic expression of a constitutively active mutant of p38 $\beta$ (p38 $\beta$ D179A) also induced Tip60-T158 phosphorylation, p53-K120 acetylation, PUMA expression and apoptosis, suggesting a possible involvement of $\mathrm{p} 38 \beta$ in this pathway (Figure $7 \mathrm{C}, 7 \mathrm{E}$ and $7 \mathrm{G})$.We thus investigated whether p38 $\beta$ is also essential for the induction of the Tip60-p53-PUMA pathway and apoptosis by DNA damage. We examined the effect of $\mathrm{p} 38 \beta$ knockdown in U2OS cells during Doxinduced DNA damage. In contrast to the control lacZ shRNA, the p38 $\beta$ shRNAs ( $\operatorname{shp} 38 \beta-652$ and shp38 $\beta-751$ ) knocked down p38 $\beta$ expression, greatly reduced the 
A

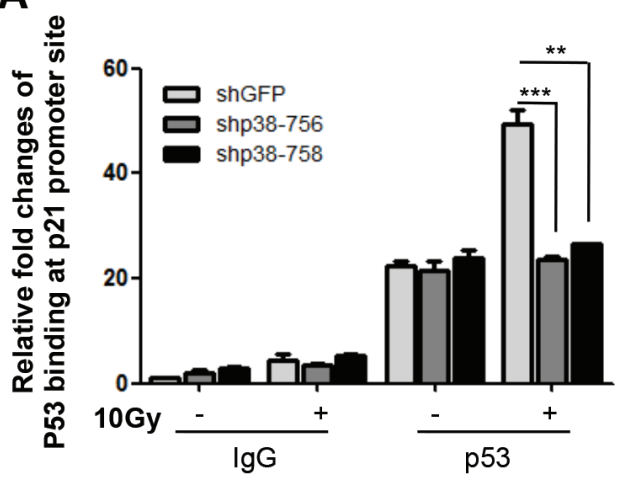

C

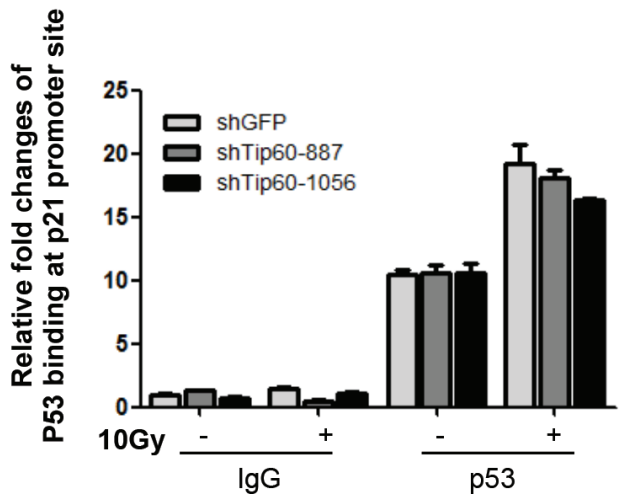

B

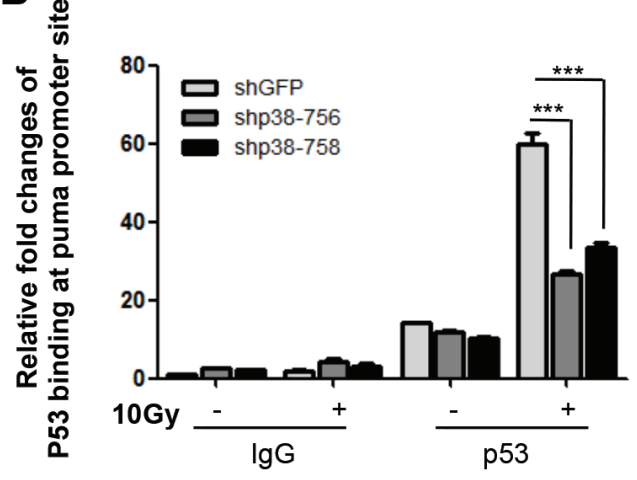

D

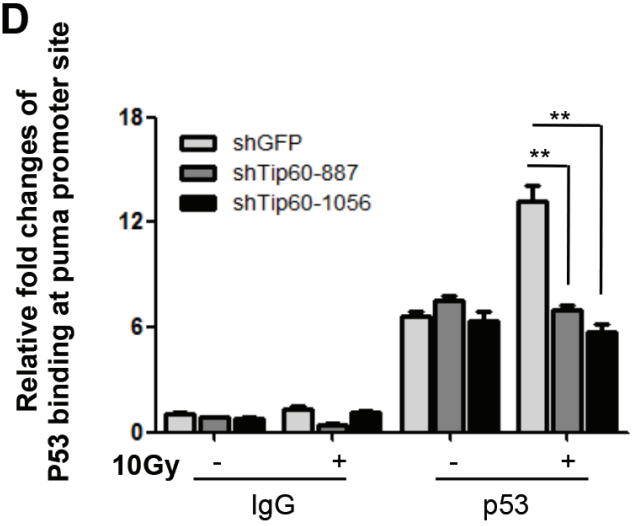

Figure 6: p38a and Tip60 are essential for DNA damage-induced binding of p53 to the PUMA promoter. (A-B) U2OS cells transduced with shRNA for GFP (shGFP) or p38 $\alpha$ (shp38 $\alpha-756$ or -758) were treated with 10 Gy of $\gamma$-radiation (10Gy) or left untreated (Ctrl) followed by incubation for $72 \mathrm{~h}$. Cells were lysed and subjected to ChIP using normal mouse IgG (IgG) or a mouse anti-p53 antibody (p53). Immunoprecipitated DNA was used as the template for real-time PCR quantification of the p53-binding sites on the p21 $1^{\text {WAF1 }}$ (A) or PUMA (B) promoters. Values are mean \pm SEM for triplicates. (C-D) U2OS cells transduced with shRNA for GFP (shGFP) or Tip60 (shTip60-887 or -1506) were treated $10 \mathrm{~Gy}$ of $\gamma$-radiation (10Gy) or left untreated (Ctrl) followed by incubation for $24 \mathrm{~h}$. Cells were lysed and subjected to ChIP using normal mouse $\operatorname{IgG}(\operatorname{IgG})$ or a mouse anti-p53 antibody (p53). Immunoprecipitated DNA was used as the template for real-time PCR quantification of the p53-binding sites on the $\mathrm{p} 21^{\mathrm{WAF} 1}$ (C) or PUMA (D) promoters. Values are mean \pm SEM for triplicates.

induction of Tip60-T158 phosphorylation and p53-K120 acetylation, and also decreased the induction of PUMA protein by Dox (Figure 8A).

We further analyzed the percentage of Annexin V-positive apoptotic cells by flow cytometry in Doxtreated cells with p38 $\beta$ knockdown. When incubated with $1 \mu \mathrm{M}$ of Dox, $9 \%$ of control cells were apoptotic, whereas p3 $8 \beta$ knockdown reduced the percentage of apoptotic cells to $4 \%$ (Figure $8 \mathrm{~B}$ and $8 \mathrm{C}$ ). This finding confirms that $\mathrm{p} 38 \beta$ is required in DNA damage-induced apoptosis.

\section{p38a is essential for DNA damage-induced Tip60-T158 phosphorylation, p53-K120 acetylation, PUMA expression and apoptosis in primary human fibroblasts}

To investigate whether the p38-Tip60-p53-PUMA signaling pathway is essential in DNA-damage induced apoptosis in the other cell lines, we knocked down p38 $\alpha$ in primary BJ human fibroblast cells using shRNA.
Consistent with the finding in U2OS cells, downregulation of $\mathrm{p} 38 \alpha$ by shRNAs ( $\operatorname{shp} 38 \alpha-756$ or shp38 $\alpha-758)$ decreased the phosphorylation Tip60 at T158, acetylation of p53 at K120 and expression of PUMA and p21 $1^{\mathrm{WAF} 1}$ induced by $1 \mu \mathrm{M}$ of Dox (Figure 9A). Moreover, p38 $\alpha$ knockdown reduced the percentage of apoptotic cells from nearly $8 \%$ to $5 \%$ in BJ cells treated with Dox (Figure 9B and 9C). Thus, the p38-Tip60-p53-PUMA pathway operates in both cancer cells and normal cells to mediate DNA damage-induced apoptosis.

\section{Phosphorylation of Tip60 at T158 by p38 is required for p53-K120 acetylation, PUMA induction and apoptosis after DNA damage}

We showed previously that p38-mediated Tip60 phosphorylation at T158 is required for the ability of Tip60 to mediate oncogene-induced senescence [20]. We thus investigated the functional relevance of this phosphorylation to DNA damage-induced responses, 
A

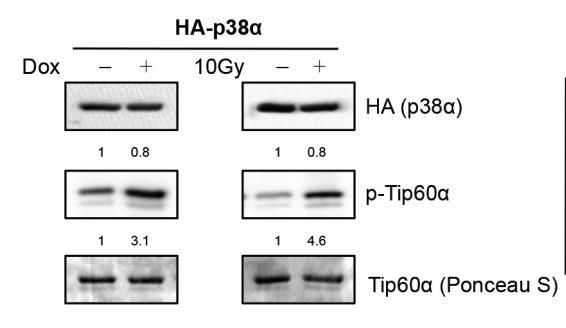

D

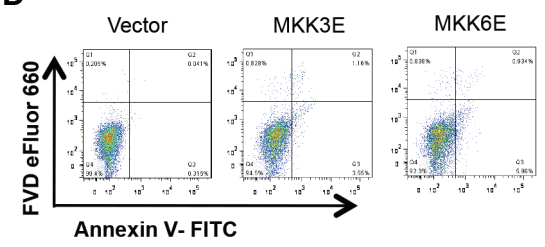

E

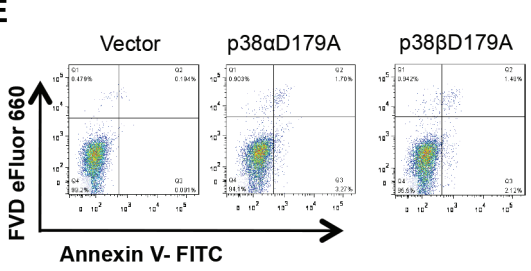

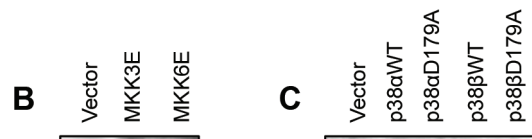
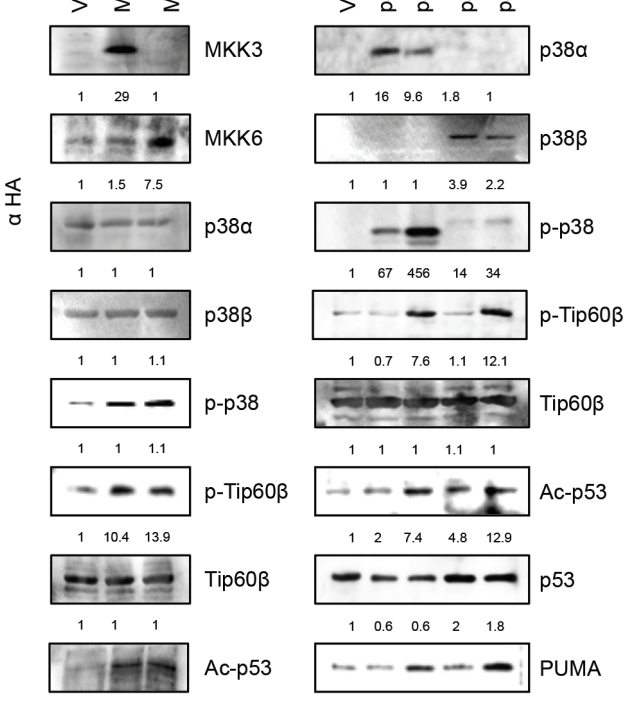

\begin{tabular}{|lllll|}
\hline 1 & 0.8 & 3.6 & 1.4 & 9.6 \\
\hline & & & & \\
\hline
\end{tabular}

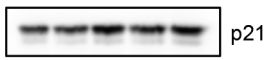

$\begin{array}{lllll}1 & 0.9 & 2 & 1.1 & 2\end{array}$

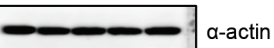

$\mathbf{F}$

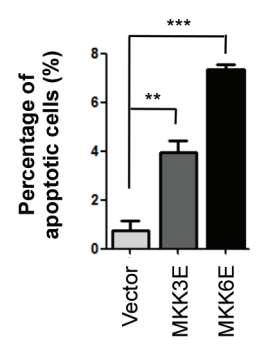

G

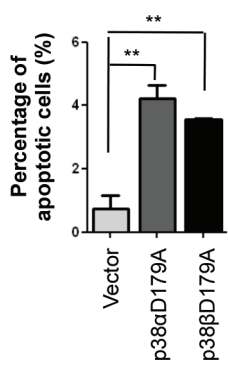

Figure 7: Activated p38a directly phosphorylates Tip60-T158 in vitro and induces Tip60-T158 phosphorylation, p53-K120 acetylation, PUMA expression and apoptosis in cells. (A) Immunoprecipitation-coupled Kinase Assays for p38 $\alpha$. HA-p38 $\alpha$ was immunoprecipitated from U2OS cells transduced with HA-p38 $\alpha$ and treated with $1 \mu \mathrm{M}$ of Dox for $36 \mathrm{~h}$ (left panels) or 10 Gy of $\gamma$-radiation followed by incubation for $48 \mathrm{~h}$ (right panels), and then incubated with recombinant Tip $60 \alpha$ in the presence of cold ATP. Immunoprecipitated HA-p38 $\alpha$ and Tip60-T158 phosphorylation were detected by Western blot using an anti-HA antibody and an anti-Tip60pT158 antibody, respectively. Input of recombinant Tip60 $\alpha$ was stained by Ponceau S. (B) Western blot analysis of U2OS cells transduced with MKK3E, MKK6E or vector (Babe-puro), detecting MKK3, MKK6, p38 $\alpha$, p383, p-p38, p-Tip60-T158, Tip60, acp53-K120, p53, PUMA, p2 $1^{\text {WAF1 }}$ and actin. Cells were lysed on day 3 post MKK3/6E transduction after selection of transduced cells. (C) Western blot analysis of U2OS cells transduced with wild-type (p38 $\alpha \mathrm{WT}, \mathrm{p} 38 \beta \mathrm{WT}$ ) or indicated active mutant of p38 isoforms

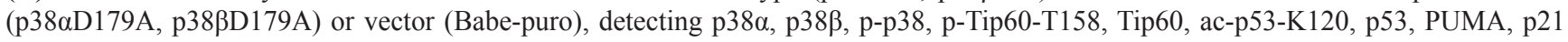
and actin. Cells were lysed on day 3 post p38 transduction after selection of transduced cells. (D) FACS analysis of U2OS cells transduced with MKK3E, MKK6E or vector. Cells were collected on day 3 post MKK3/6E transduction after selection of transduced cells, and stained with a FITC-conjugated anti-Annexin-V antibody and FVD eFlour 660. (E) FACS analysis of U2OS cells transduced with wild-type

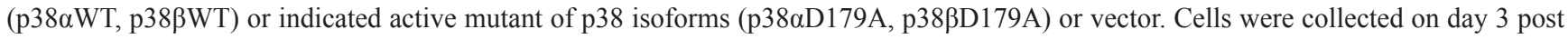
p38 transduction after selection of transduced cells, and stained with a FITC-conjugated anti-Annexin-V antibody and FVD eFlour 660. (F) Quantification and statistical analysis of the data in D. The percentage of apoptotic cells was quantified as the percentage of FITCpositive cells in the gated area. Values are mean \pm SEM for triplicates. (G) Quantification and statistical analysis of the data in E. The percentage of apoptotic cells was quantified as the percentage of FITC-positive cells in the gated area. Values are mean $\pm \mathrm{SEM}$ for triplicates. 

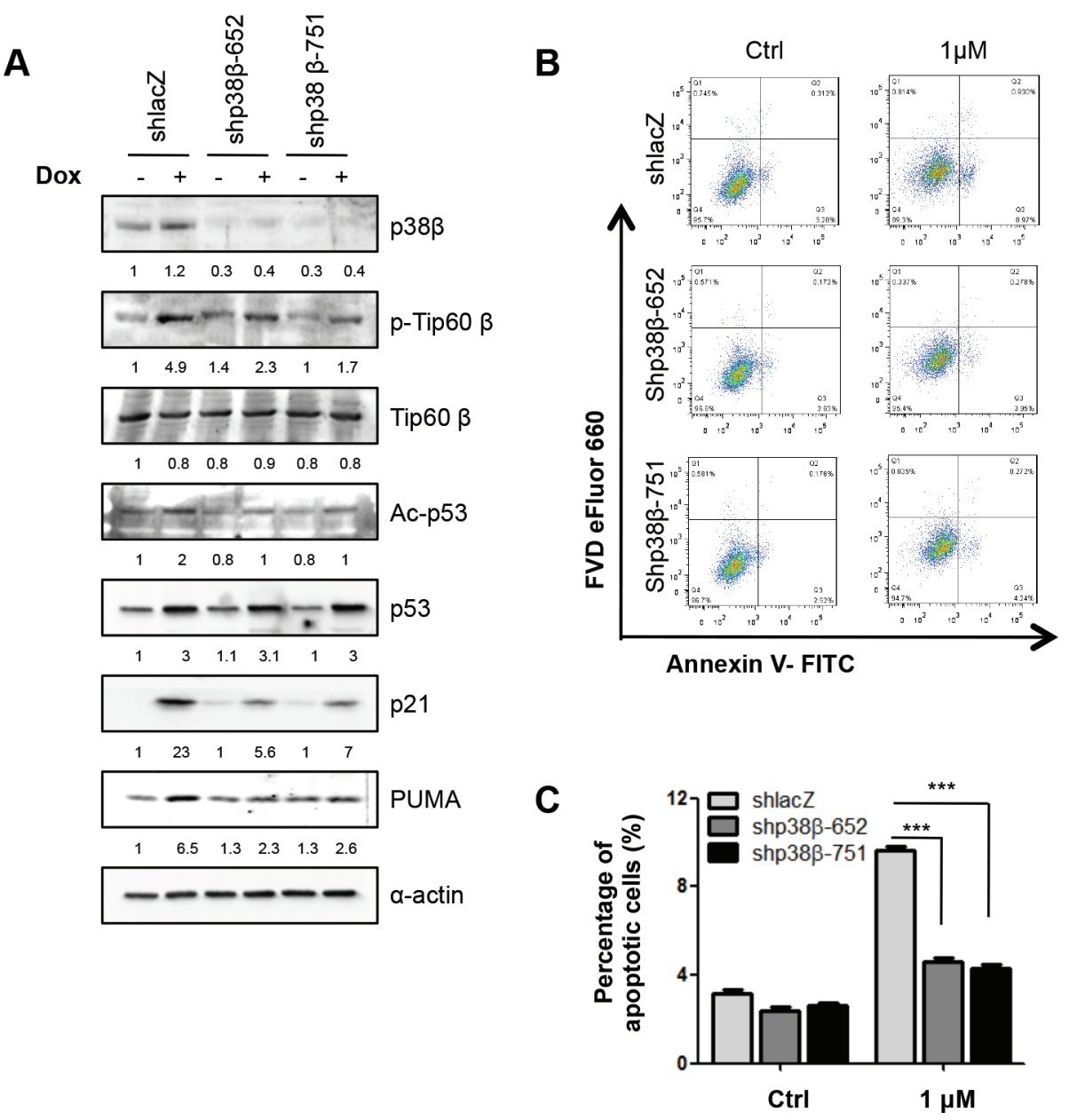

Figure 8: p38 $\beta$ is also essential for Tip60-T158 phosphorylation, p53-K120 acetylation, PUMA expression and

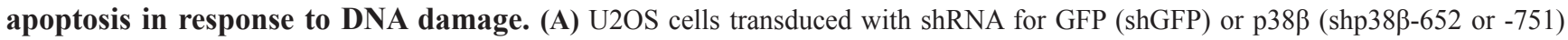
were treated with $1 \mu \mathrm{M}$ of Dox for $36 \mathrm{~h}$. Cell lysis was subjected to Western blot analysis detecting the indicated proteins. (B) U2OS cells

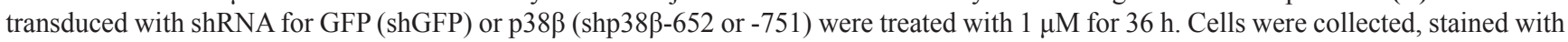
an FITC-conjugated anti-Annexin-V antibody and FVD eFlour 660 and analyzed by FACS. (C) Quantification and statistical analysis of the data in B. The percentage of apoptotic cells was quantified as the percentage of FITC-positive cells in the gated area. Values are mean \pm SEM for triplicates.

including p53 acetylation at K120, PUMA expression, and apoptosis. As shown previously, Tip60 shRNAs (shTip60-887 and -1506) reduced induction of p53 acetylation at K120 and PUMA expression by $1 \mu \mathrm{M}$ or $3 \mu \mathrm{M}$ of Dox or 10 Gy of $\gamma$-radiation (Figure 10A-10D). Ectopic expression of murine Tip60, which could not be knocked down by human Tip60 shRNA (Figure, 10A and 10B), restored DNA damage-induced p53-K120 acetylation (Figure 10A and 10B) and expression of PUMA at both protein level (Figure 10A and 10B) and mRNA level (Figure 10C and 10D) in U2OS cells expressing human Tip60 shRNA, indicating that murine Tip60 can functionally replace human Tip60 in these responses to DNA damage. In contrast, murine Tip60 carrying the T158A mutation, which cannot be phosphorylated by $\mathrm{p} 38$, failed to restore the induction of p53-K120 acetylation and PUMA expression by DNA damage in the presence of the human Tip60 shRNA (Figure 10A-10D). Therefore, phosphorylation of Tip60 at T158 is essential for the ability of Tip60 to mediate DNA damage-induced p53-K120 acetylation and PUMA expression. Neither Tip60 shRNA nor ectopic expression of murine Tip60 altered induction of $\mathrm{p} 21^{\mathrm{WAF}}$ by DNA damage (Figure 10A and 10B), confirming that Tip60 does not play a critical role in the regulation of $\mathrm{p} 21^{\mathrm{WAF} 1}$ expression in DNA damage.

We further explored the importance of phosphorylation of Tip60 at T158 in DNA damageinduced apoptosis. While Tip60 shRNA decreased the percentage of apoptotic cells induced by $1 \mu \mathrm{M}$ or $3 \mu \mathrm{M}$ of Dox or 10 Gy of $\gamma$-radiation, ectopic expression of wild type murine Tip60 restored induction of apoptosis in U2OS cells expression human Tip60 shRNA after DNA damage; however, the T158A mutant of murine Tip60 
BJ

A

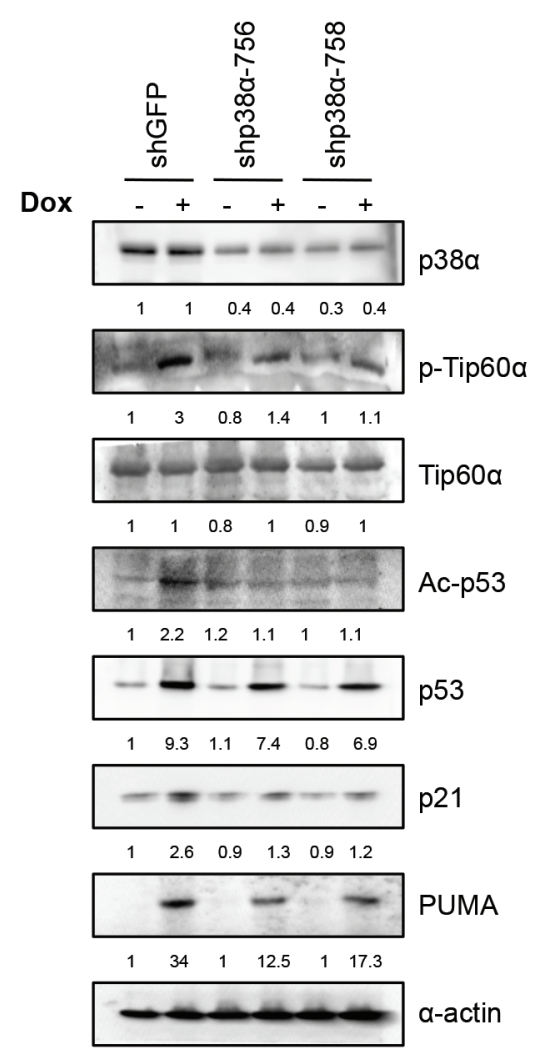

B

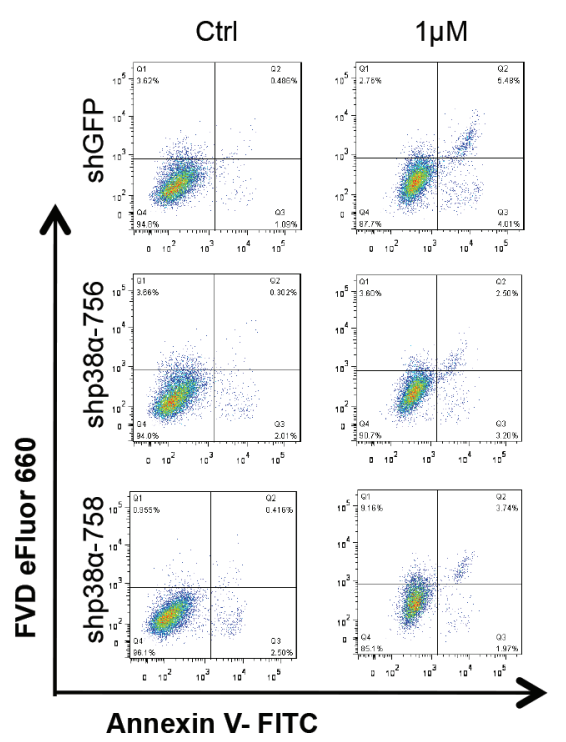

C

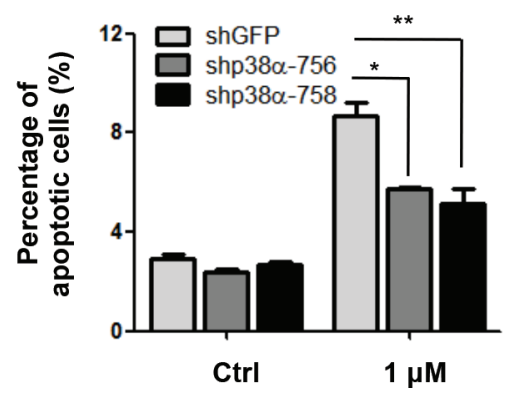

Figure 9: p38 $a$ is essential for DNA damage-induced Tip60-T158 phosphorylation, p53-K120 acetylation, PUMA expression and apoptosis in primary human fibroblasts. (A) BJ cells transduced with shRNA for GFP (shGFP) or p38a (shp38a-756 or -758) were treated with $1 \mu \mathrm{M}$ of Dox for $24 \mathrm{~h}$. Cell lysis was subjected to Western blot analysis detecting the indicated proteins. (B) BJ cells transduced with shRNA for GFP (shGFP) or p38 $\alpha$ (shp38 $\alpha-756$ or -758 ) were treated with $1 \mu \mathrm{M}$ for $24 \mathrm{~h}$. Cells were collected, stained with an FITC-conjugated anti-Annexin-V antibody and FVD eFlour 660 and analyzed by FACS. (C) Quantification and statistical analysis of the data in B. The percentage of apoptotic cells was quantified as the percentage of FITC-positive cells in the gated area. Values are mean \pm SEM for triplicates.

failed to restore apoptosis abrogated by human Tip60 shRNA (Figure 11A-11D).

Taken together, these findings indicate that $\mathrm{p} 38$ mediated Tip60 phosphorylation at T158 plays an essential role in p53 acetylation at K120 and activation, induction of PUMA expression and induction of apoptosis during DNA damages.

\section{DISCUSSION}

In a previous study, we identified p38 as a Tip60 kinase that induces the acetyltransferase activity of Tip60 by phosphorylating Tip60 at T158 [20]. In that same study, we demonstrated that upon phosphorylation and activation by $\mathrm{p} 38$, Tip60 mediates oncogene-induced senescence through acetylation of a downstream substrate PRAK. Tip60 is a multifunctional acetyltransferase that has been shown to mediate multiple cellular processes by acetylating different substrate proteins $[20,24,32]$. One important function of Tip60 is to mediate DNA damageinduced apoptosis by acetylating p53 at K120 and thus stimulating the ability of p53 to induce PUMA [14]. We thus investigated the effect of p38-mediated Tip60 phosphorylation on the p53-PUMA pathway during DNA damage-induced apoptosis in the current study. We showed that p38 activation, Tip60-T158 phosphorylation, and p53-K120 acetylation are induced with similar kinetics by DNA damage. $\mathrm{p} 38 \alpha$ is essential for DNA damage-induced Tip60 phosphorylation at T158. In addition, both $\mathrm{p} 38$ and Tip60 are essential for p53 acetylation at K120, binding 
A

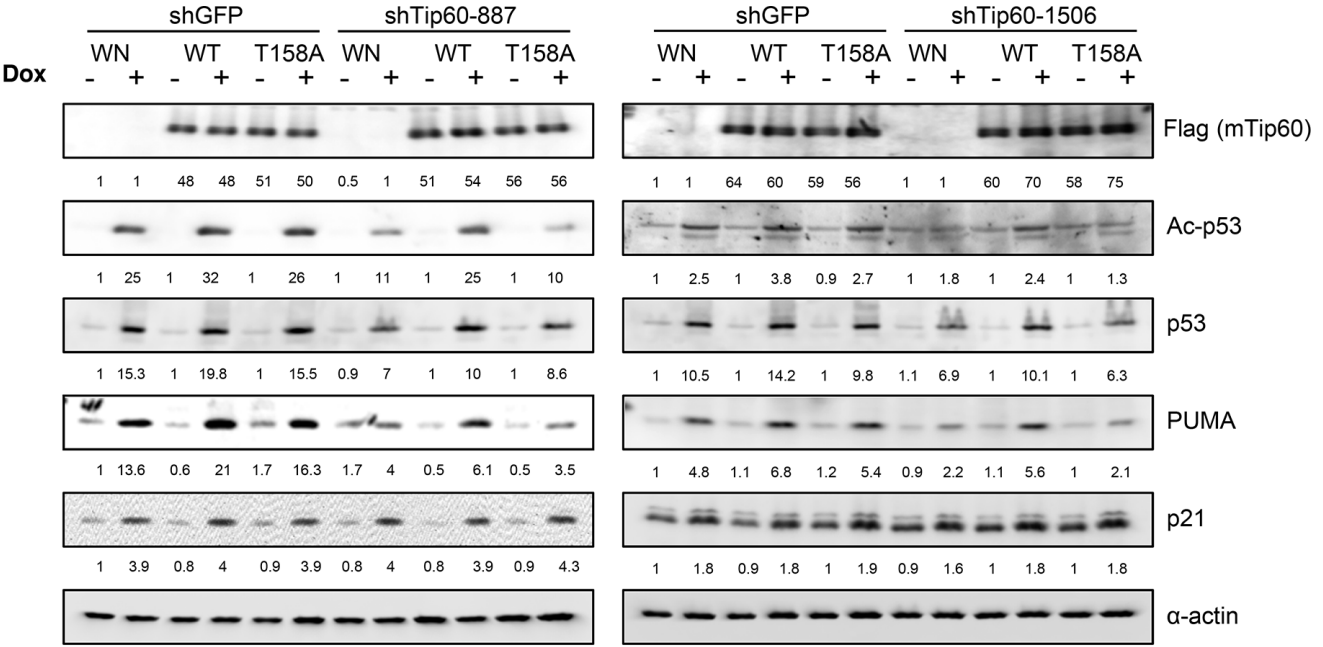

B
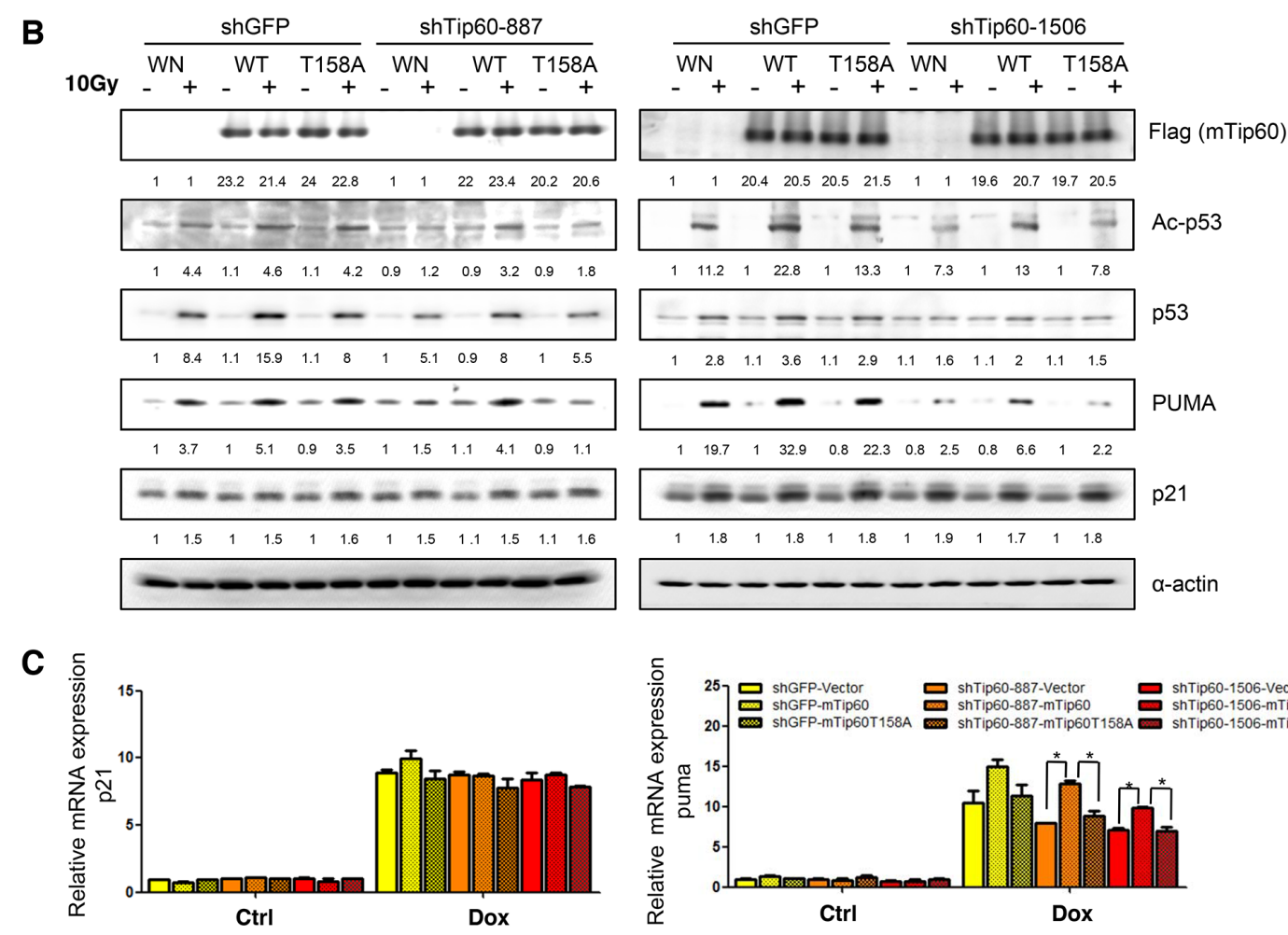

D
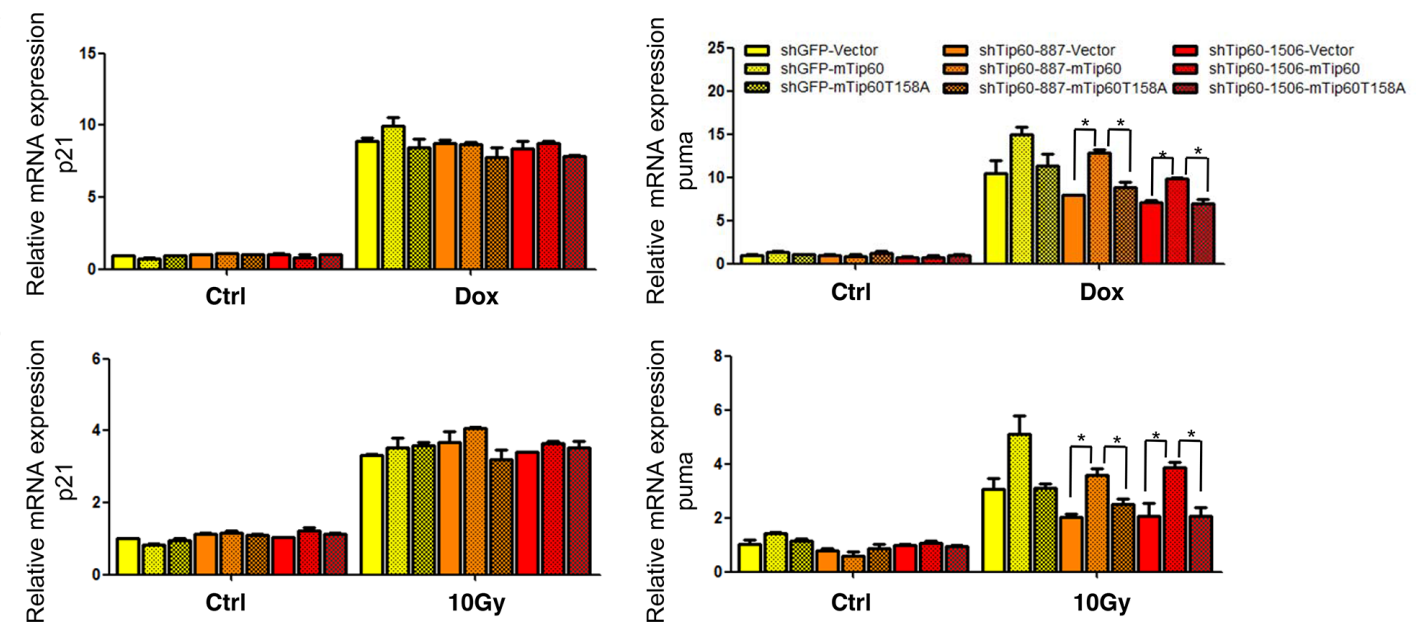

Figure 10: Phosphorylation of Tip60 at T158 by p38a is required for p53-K120 acetylation and PUMA induction after DNA damage. (A-B) U2OS cells were co-transduced with shRNA for GFP (shGFP) or Tip60 (shTip60-887 or -1506) and vector (WN), wild type mouse Tip60 (WT) or mutant mouse Tip60 (T158A). Cells were treated with $1 \mu \mathrm{M}$ of Dox for $36 \mathrm{~h}$ (A) or 10 Gy of $\gamma$-radiation followed by incubation for $24 \mathrm{~h}$ (B). Cell lysis was subjected to Western blot analysis detecting the indicated proteins. (C-D) U2OS cells were co-transduced with shRNA for GFP (shGFP) or Tip60 (shTip60-887 or -1506) and vector (WN), wild type mouse Tip60 (WT) or mutant mouse Tip60 (T158A). Cells were treated with $1 \mu \mathrm{M}$ of Dox for $36 \mathrm{~h}$ (C) or $10 \mathrm{~Gy}$ of $\gamma$-radiation followed by incubation for $24 \mathrm{~h}$ (D) mRNA levels of PUMA (right panels) and $221^{\text {WAF1 }}$ (left panels) were detected by real-time PCR. Values are mean \pm SEM for triplicates. 

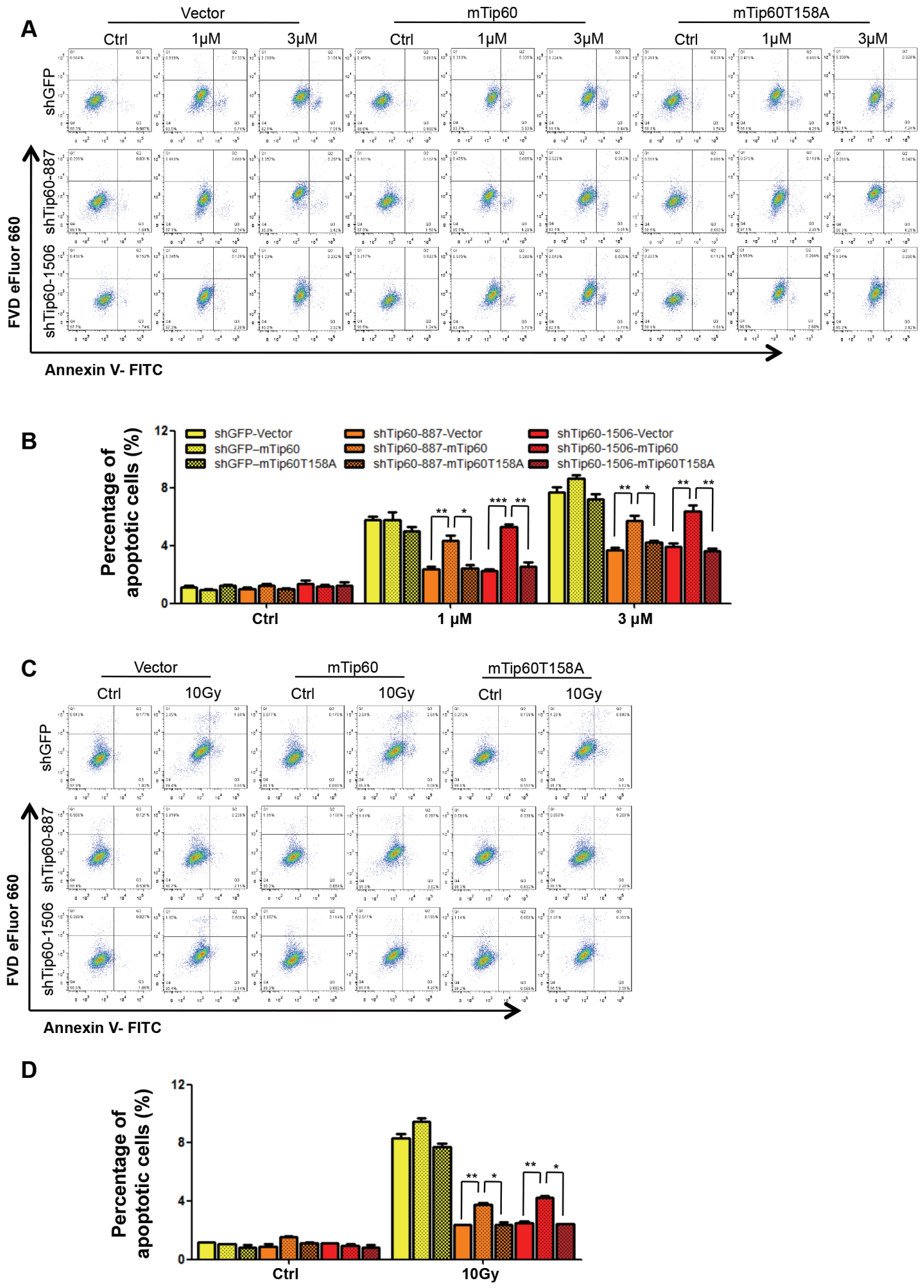

Figure 11: Phosphorylation of Tip60 at T158 by p38a is required for apoptosis induction in response to DNA damage. (A and C) U2OS cells were co-transduced with shRNA for GFP (shGFP) or Tip60 (shTip60-887 or -1506) and vector (WN), wild type mouse Tip60 (WT) or mutant mouse Tip60 (T158A), and treated with $1 \mu \mathrm{M}$ or $3 \mu \mathrm{M}$ of Dox for $24 \mathrm{~h}$ (A) or 10 Gy of $\gamma$-radiation followed by incubation for $24 \mathrm{~h}(\mathrm{C})$. Cells were collected, stained with a FITC-conjugated anti-Annexin-V antibody and FVD eFlour 660, and analyzed by FACS. (B and D) Quantification and statistical analysis of the data in A (B) or C (D). The percentage of apoptotic cells was quantified as the percentage of FITC-positive cells in the gated area. Values are mean \pm SEM for triplicates. 
of p53 to the PUMA promoter, PUMA expression and apoptosis induced by DNA damage. Moreover, DNA damage induces the protein kinase activity of p38a towards Tip60-T158, and constitutive activation of p38 leads to increases in Tip60-T158 phosphorylation, p53-K120 acetylation, PUMA expression and apoptosis in cells. Furthermore, the Tip60-T158A mutant that cannot be phosphorylated by $\mathrm{p} 38$ failed to mediate p53-K120 acetylation, PUMA induction, and apoptosis following DNA damage. These results establish that Tip60-T158 phosphorylation by $\mathrm{p} 38$ plays an essential role in engaging the Tip60 activity required for inducing the p53-PUMA pathway that ultimately leads to apoptosis in response to DNA damage. These findings are consistent with previous reports showing that DNA damage induced apoptosis requires activation of $\mathrm{p} 38$ [33-34].

Both p38 $\alpha$ and Tip60 have been shown to have tumor suppressing activities [21,35-36]. Deletion of either $\mathrm{p} 38 \alpha$ or Tip60 accelerates cancer development in mouse. Since p53-mediated apoptosis is an efficient cellular process that eliminates cells with potential oncogenic mutations resulted from unrepaired DNA damage, the essential role of p38 $\alpha$ and Tip60 in DNA damage-induced apoptosis provides a mechanistic basis underlying the tumor suppressing function of these two proteins. Deletion of p38 $\alpha$ and Tip60 may disrupt apoptosis of cells with unrepaired DNA, leading to accumulation of cells with oncogenic alterations and enhanced cancer development.

Consistent with the report that acetylation of p53-K120 by Tip60 only stimulates the ability of p53 to induce PUMA, but not $\mathrm{p} 21^{\mathrm{WAF} 1}$, Tip60 shRNA reduced DNA damage-induced binding of p53 to the PUMA promoter and PUMA expression, but did not alter the binding of $\mathrm{p} 53$ to the $\mathrm{p} 21^{\mathrm{WAF} 1}$ promoter or $\mathrm{p} 21^{\mathrm{WAF} 1}$ expression. The T158A mutation of Tip60 also only abrogated the ability of Tip60 to mediate the induction of PUMA after DNA damage, without affecting p $21^{\text {WAF1 }}$ induction, suggesting that phosphorylation of Tip60 by p38 specifically regulates the p53-PUMA axis and apoptosis. In contrast, $\mathrm{p} 38 \alpha$ knockdown abrogated binding of $\mathrm{p} 53$ to both PUMA and $\mathrm{p} 21^{\mathrm{WAF} 1}$ promoters and reduced induction of both PUMA and $\mathrm{p} 21^{\mathrm{WAF} 1}$ upon DNA damage. This indicates that in addition to phosphorylating Tip60 and promoting its activity towards the p53-PUMA axis, p38 activates another Tip60-independent pathway that stimulates the ability of $\mathrm{p} 53$ to induce $\mathrm{p} 21^{\mathrm{WAF} 1}$. Indeed, it has been shown that $\mathrm{p} 38$ can regulate $\mathrm{p} 53$ activity by directly phosphorylating p53 at S33 and S46 in response to UV radiation [37]. In addition, p38 can phosphorylate a mRNA binding protein HuR at Thr118 in response to DNA damage, leading to accumulation of HuR in cytoplasma, which binds to and stabilizes the mRNA of $\mathrm{p} 21^{\mathrm{WAF} 1}$ [38]. It is thus likely that $\mathrm{p} 38$ regulates DNA damage-induced apoptosis and cell cycle arrest through multiple pathways.
In addition to direct acetylation of p53 at K120, Tip60 has also been shown to regulate the activity of p53 as a transcriptional coactivator on p53 target promoters. While our data clearly indicate that phosphorylation of Tip60 by $\mathrm{p} 38$ contributes to p53 activation through direct acetylation of K120, further studies are needed to investigate the role of p38-mediated Tip60 phosphorylation in the function of Tip60 as a transcriptional coactivator of p53. Moreover, another member of the MYST family of acetyltransferases, hMOF, also phosphorylates p53 at $\mathrm{K} 120$. It will be interesting to investigate whether hMOF is phosphorylated and activated by $\mathrm{p} 38$ and contributes to $\mathrm{p} 53$ activation following DNA damage.

Although our studies clearly identify p38 a as the p38 isoform that phosphorylates Tip60-T158 and mediates the subsequent acetylation of p53-K120 and p53-mediated apoptosis following DNA damage, our data indicate that $\mathrm{p} 38 \beta$ is also involved in this pathway. Ectopic expression of the constitutively active mutants of both $\mathrm{p} 38 \alpha$ and $\mathrm{p} 38 \beta$ induced Tip60-T158 phosphorylation, p53-K120 acetylation, PUMA expression and apoptosis, whereas both $p 38 \alpha$ and $p 38 \beta$ shRNAs abrogated these same changes induced by DNA damage. We propose that p38 $\alpha$ and p38 $\beta$ have the same function in this pathway and mediate DNA damage-induced apoptosis through an identical mechanism. The knockdown of either p38 $\alpha$ or p38 $\beta$ alone reduces the amount of total p38 in cells, thus leading to a decrease in the signaling strength of the p38Tip60-p53-PUMA pathway and abrogation of apoptosis induction. Further experiments are needed to define the role of the other $\mathrm{p} 38$ isoforms in Tip60 phosphorylation and 553 -mediated apoptosis in response to DNA damage. Indeed, a previous report showed that all $4 \mathrm{p} 38$ isoforms are activated by $\gamma$-radiation in U2OS cells [39]. Using dominant negative mutants of $\mathrm{p} 38$ isoforms, this paper further demonstrated that $\mathrm{p} 38 \gamma$, but not the other isoforms, is required for $\gamma$-radiation-induced G2 cell cycle arrest. It is thus possible that various p38 isoforms contribute to different aspects of the DNA damage response, such as apoptosis and cell cycle arrest.

\section{MATERIALS AND METHODS}

\section{Cell culture}

U2OS cells and LinX-A retroviral packaging cells were maintained in Dulbecco's modified eagle's medium supplemented with $10 \%$ fetal calf serum, sodium pyruvate, and antibiotics. 293T cells were grown in DMEM with $10 \%$ fetal calf serum, sodium pyruvate, glutamine, and antibiotics. BJ primary human fibroblasts were maintained in Minimum Essential Medium supplemented with 10\% fetal calf serum, nonessential amino acids, glutamine, and antibiotics. 


\section{Plasmids}

Oligonucleotides for small hairpin RNAs (shRNAs) targeting p38 $3-652$ (AAAAGCATTACAACCAA ACAGTGTTGGATC CAACACTGTTTGGTTGTAAT), p38ß-751 (AAAAGCTGAAGCG CATCATGGAATT GGATCCAAT TCCATGATGCGCTTCA), and LacZ (AAAA-GCAGTTATCTGGAAGATCAGGTTGGATCCAA-CCTGATCTTCCAGA TAACTGC) were cloned into $\mathrm{pLV}$-EF1 $\alpha$-Puro lentiviral expression vectors (Biosettia, San Diego, CA) according to the manufacturer's protocol. Retroviral vectors encoding shRNAs targeting p38 $\alpha$ [27], Tip60 [20] and p53 [40], expression vectors for mTip60 and mTip60T158A [20], and those for HA-p38 $\alpha$, MKK3E, MKK6E [40], as well as wild type and constitutive active mutants of $\mathrm{p} 38$ isoforms [27] were described previously.

\section{Retrovirus- and lentivirus-based gene transduction}

Recombinant retroviruses were packaged and transduced into $\mathrm{U} 2 \mathrm{OS}$ or BJ cells as previously described [41]. Recombinant pLV-EF1 $\alpha$-Puro lentiviruses were packaged in 293T cells following the manufacturer's protocol (Biosettia, San Diego, CA) and transduced into U2OS cells as previously described [42]. Transduced cells were purified with $80 \mu \mathrm{g} / \mathrm{ml}$ hygromycin B, and $/$ or $2 \mu \mathrm{g} / \mathrm{ml}$ puromycin.

\section{Analysis of apoptosis}

$\mathrm{U} 2 \mathrm{OS}$ or BJ cells were seeded into $15 \mathrm{~cm}$ plates at a density of $2 \times 10^{6}$ cells/plate. After treated with $1 \mu \mathrm{M}$ or $3 \mu \mathrm{M}$ Doxorubicin (Cat\# 65-0864-14, Sigma, MO) for $24 \mathrm{~h}$ or exposure to $10 \mathrm{~Gy} \gamma$-radiation followed by incubation for $16 \mathrm{~h}$ or $72 \mathrm{~h}$, cells were harvested by trypsinization (Cat\# 17-160E, Lonza, NJ), and combined with cells collected from suspension, after which cells were collected by centrifugation, washed with PBS, stained with Fixable Viability Dye eFluor ${ }^{\circledR} 660$ (Cat\# 65-0864-14, eBioscience, CA) for $30 \mathrm{~min}$, and then wash with PBS and Annexin-V binding buffer (Cat\# 88-8005, eBioscience, CA). $5 \mu 1$ of FITC-conjugated Annexin-V (Cat\# 888005 , eBioscience, CA) were added and incubated with cells at room temperature for $15 \mathrm{~min}$. The percentage of FITC-positive apoptotic cells were determined by flow cytometry. Each experimental point was performed in triplicates.

\section{Western blot analysis}

U2OS or BJ cells were seeded into $15 \mathrm{~cm}$ plates at a density of $2 \times 10^{6}$ cells/plate and treated with indicated dosages of Doxorubicin or $\gamma$ radiation. Cell lysates were prepared in RIPA buffer described previously
[43]. Cleared cell lysates were subjected to SDS-PAGE using 10 or $15 \%$ polyacrylamide gel and transferred to nitrocellulose membranes. The primary antibodies were from Cell Signaling (p38-pT180Y182, p38 $\alpha$ and HA-tag), Santa Cruz (p53, p21 $\left.{ }^{\text {WAF1 }}\right)$, Prosci (PUMA), Abcam (ac$\mathrm{p} 53-\mathrm{K} 120)$ or Sigma ( $\alpha$-actin). The rabbit anti-Tip60 and p-Tip60-T158 antibody were raised in our lab [20].

\section{Quantitative real-time PCR}

RNA was isolated from cells by using TRIzol reagent and converted to cDNA using iScript Reverse Transcription Supermix (Cat\# 170-8840, Bio-Rad, CA) according to the manufacturer's protocol. Quantitative real-time reverse transcription-PCR (qRT-PCR) was performed using Sso Advanced SYBR green Supermix (Cat\# 172-5271, Bio-Rad, CA) on a CFX96 realtime system (Bio-Rad). Signals were normalized to that of a housekeeping gene, $\beta$-actin. The primers used were 5'-TCAACGCACAGTACGAGCG-3' and 5'-TGGGTAAGGGCAGGAGTCC-3' for PUMA, 5'-TGTCACTGTCTTGTACCCTTG-3' and 5'-GGCGTTTGGAGTGGTAGAA-3' for p21, 5'-GGCATCCACGAAACTACCTT-3' and $5^{\prime}$-CTCGTCATACTCCTGCTTGC-3' $5^{1}$ for $\beta$-actin.

\section{ChIP assays}

U2OS cells were seeded into $15 \mathrm{~cm}$ plates at a density of $2 \times 10^{6}$ cells/plate and treated with $10 \mathrm{~Gy}$ of $\gamma$ radiation for $16 \mathrm{~h}$ or $72 \mathrm{~h}$. ChIP assays were performed as described before [41]. After sonication, $10 \%$ of each sample was saved as total input, $45 \%$ of each sample was incubated with $5 \mu \mathrm{g}$ of anti-p53 antibody (Cat\# sc-126, Santa Cruz, TX), and the remaining $45 \%$ of each sample was incubated with $5 \mu \mathrm{g}$ of normal mouse IgG (Cat\# sc-2025, Santa Cruz, TX) at $4^{\circ} \mathrm{C}$ overnight and then with $50 \mu \mathrm{l}$ (bead volume) of Pure Proteome proteinG magnetic beads (Cat\# LSKMAGG02, Millipore, CA) at $4^{\circ} \mathrm{C}$ for $4 \mathrm{~h}$. After wash and reverse crosslinking, DNA was extracted with phenolchloroform, precipitated with ethanol, and dissolved in $\mathrm{H}_{2} \mathrm{O} .2 \mu \mathrm{l}$ of ChIP material and $1 \mu \mathrm{l}$ of $1: 10$ dilution of total input were quantified by real-time PCR using primers amplifying the region from-1449 to -1342 of the PUMA promoter [3-4] (5'-TCCTCCTTGCCTGGGCTAG-3' and 5'-GCGGACAAGTCAGGACTTGC-3') or those amplifying the region from -1463 to -1271 of the $\mathrm{p} 21^{\mathrm{WAF} 1}$ promoter (5'-GGGTCTGCTACTGTGTCCTC -3'and 5'-TTGGTGCAGCTACAATTACTG-3'). All the ChIPqPCR data were normalized to the Input-qPCR data following Percent Input Method [44].

\section{Recombinant proteins}

Recombinant His-Tip60 $\alpha$ was prepared as described previously [20]. 


\section{Immunoprecipitation-coupled kinase assays for $\mathrm{p38a}$}

U2OS cells were lysed in a buffer containing $50 \mathrm{mM}$ HEPES, pH 7.5, $2.5 \mathrm{mM}$ EGTA, $1 \mathrm{mM}$ EDTA, $1 \%$ Triton X-100, $150 \mathrm{mM} \mathrm{NaCl}, 10 \%$ glycerol, $1 \mathrm{mM}$ phenylmethylsulfonyl fluoride, $50 \mathrm{mM} \mathrm{NaF}, 1 \mathrm{mM}$ sodium vanadate, $1 \mathrm{mM} \beta$-glycerophosphate, $1 \mathrm{mM}$ dithiothreitol, and Complete protease inhibitors. $500 \mu \mathrm{g}$ of lysate were incubated with $2.5 \mu \mathrm{g}$ of $\mathrm{p} 38 \alpha$ rabbit polyclonal antibody or HA-11 mouse monoclonal antibody (Covance) at $4^{\circ} \mathrm{C}$ overnight, after which $30 \mu \mathrm{l}$ of Protein $\mathrm{A} / \mathrm{G}$ agarose or Protein $\mathrm{G}$ agarose (Pierce) were added and incubated for additional $2 \mathrm{~h}$. The beads were washed two times with $1 \mathrm{ml}$ of lysis buffer and two times with kinase buffer (50 mM HEPES, pH 7.5, 0.5 mM EGTA, $10 \mathrm{mM} \mathrm{MgCl2,}$ $0.1 \mathrm{mM}$ phenylmethylsulfonyl fluoride, $1 \mathrm{mM} \mathrm{NaF}, 0.1$ $\mathrm{mM}$ sodium vanadate, $0.1 \mathrm{mM} \beta$-glycerophosphate, and $1 \mathrm{mM}$ dithiothreitol). The reactions were performed in $20 \mu \mathrm{l}$ of kinase buffer (above) with $20 \mu \mathrm{M}$ cold ATP, and $10 \mu \mathrm{g}$ of recombinant His-Tip $60 \alpha$ at $30^{\circ} \mathrm{C}$ for $45 \mathrm{~min}$. The reactions were stopped by $7 \mu$ of $4 \times$ Laemmli buffer, heated at $95^{\circ} \mathrm{C}$, and the supernatants were subjected to Western blot analysis. HA-p38 was detected by a rabbit HA antibody (Cell signaling) and p38 $\alpha$ was detected by a mouse p38 $\alpha$ antibody (Cell signaling).

\section{Statistical analysis}

Values were expressed as Means \pm S.E.M. Significance were determined by Student's $t$-test. A value of $p<0.05$ was used as the criterion for statistical significance. $*$ indicates significant difference with $p<$ $0.05, * *$ indicates significant difference with $p<0.01$, $* * *$ indicates significant difference with $p<0.001$.

\section{ACKNOWLEDGMENTS}

This work is supported by the National Institutes of Health (CA131231 and CA172115) and the Overseas Cooperation Fund from the National Natural Science Foundation of China (31428013).

\section{REFERENCES}

1. Rebbaa A, Zheng X, Chou PM, Mirkin BL. Caspase inhibition switches doxorubicin-induced apoptosis to senescence. Oncogene. 2003; 22:2805-2811.

2. Krenning L, Feringa FM, Shaltiel IA, van den Berg J, Medema RH. Transient Activation of p53 in G2 Phase Is Sufficient to Induce Senescence. Molecular cell. 2014; 55:59-72.

3. Wang $\mathrm{P}, \mathrm{Yu}$ J, Zhang L. The nuclear function of $\mathrm{p} 53$ is required for PUMA-mediated apoptosis induced by
DNA damage. Proceedings of the National Academy of Sciences of the United States of America. 2007; 104: 4054-4059.

4. Gomes NP, Espinosa JM. Gene-specific repression of the p53 target gene PUMA via intragenic CTCF-Cohesin binding. Genes \& development. 2010; 24:1022-1034.

5. Yu J, Zhang L, Hwang PM, Kinzler KW, Vogelstein B. PUMA induces the rapid apoptosis of colorectal cancer cells. Molecular cell. 2001; 7:673-682.

6. Yu J, Zhang L. PUMA, a potent killer with or without $\mathrm{p} 53$. Oncogene. 2008; 27:S71-83.

7. Nakano K, Vousden KH. PUMA, a novel proapoptotic gene, is induced by p53. Molecular cell. 2001; 7:683-694.

8. Kruse JP, Gu W. Modes of p53 regulation. Cell. 2009; 137:609-622.

9. Luo J, Su F, Chen D, Shiloh A, Gu W. Deacetylation of p53 modulates its effect on cell growth and apoptosis. Nature. 2000; 408:377-381.

10. Sakaguchi K, Herrera JE, Saito S, Miki T, Bustin M, Vassilev A, Anderson CW, Appella E. DNA damage activates p53 through a phosphorylation-acetylation cascade. Genes Dev. 1998; 12:2831-2841.

11. Gu W, Shi XL, Roeder RG. Synergistic activation of transcription by CBP and p53. Nature. 1997; 387:819-823.

12. Liu L, Scolnick DM, Trievel RC, Zhang HB, Marmorstein $\mathrm{R}$, Halazonetis TD, Berger SL. p53 sites acetylated in vitro by PCAF and p300 are acetylated in vivo in response to DNA damage. Mol Cell Biol. 1999; 19:1202-1209.

13. Tang Y, Zhao W, Chen Y, Zhao Y, Gu W. Acetylation is indispensable for p53 activation. Cell. 2008; 133:612-626.

14. Tang Y, Luo J, Zhang W, Gu W. Tip60-dependent acetylation of p53 modulates the decision between cellcycle arrest and apoptosis. Molecular cell. 2006; 24: 827-839.

15. Squatrito M, Gorrini C, Amati B. Tip60 in DNA damage response and growth control: many tricks in one HAT. Trends Cell Biol. 2006; 16:433-442.

16. Sapountzi V, Logan IR, Robson CN. Cellular functions of TIP60. Int J Biochem Cell Biol. 2006; 38:1496-1509.

17. Doyon Y, Selleck W, Lane WS, Tan S, Cote J. Structural and functional conservation of the NuA4 histone acetyltransferase complex from yeast to humans. Mol Cell Biol. 2004; 24:1884-1896.

18. Charvet C, Wissler M, Brauns-Schubert P, Wang SJ, Tang Y, Sigloch FC, Mellert H, Brandenburg M, Lindner SE, Breit B, Green DR, McMahon SB, Borner C, Gu W, Maurer U. Phosphorylation of Tip60 by GSK-3 determines the induction of PUMA and apoptosis by p53. Molecular cell. 2011; 42:584-596.

19. Ikura T, Ogryzko VV, Grigoriev M, Groisman R, Wang J, Horikoshi M, Scully R, Qin J, Nakatani Y. Involvement of the TIP60 histone acetylase complex in DNA repair and apoptosis. Cell. 2000; 102:463-473. 
20. Zheng H, Seit-Nebi A, Han X, Aslanian A, Tat J, Liao R, Yates JR 3rd, Sun P. A posttranslational modification cascade involving p38, Tip60, and PRAK mediates oncogeneinduced senescence. Molecular cell. 2013; 50:699-710.

21. Gorrini C, Squatrito M, Luise C, Syed N, Perna D, Wark L, Martinato F, Sardella D, Verrecchia A, Bennett S, Confalonieri S, Cesaroni M, Marchesi F, Gasco M, Scanziani E, Capra M, et al. Tip60 is a haplo-insufficient tumour suppressor required for an oncogene-induced DNA damage response. Nature. 2007; 448:1063-1067.

22. Kurz EU, Douglas P, Lees-Miller SP. Doxorubicin activates ATM-dependent phosphorylation of multiple downstream targets in part through the generation of reactive oxygen species. The Journal of biological chemistry. 2004; 279:53272-53281.

23. Sykes SM, Mellert HS, Holbert MA, Li K, Marmorstein R, Lane WS, McMahon SB. Acetylation of the p53 DNAbinding domain regulates apoptosis induction. Molecular cell. 2006; 24:841-851.

24. Liu N, Wang J, Wang J, Wang R, Liu Z, Yu Y, Lu H. ING5 is a Tip60 cofactor that acetylates p53 in response to DNA damage. Cancer research. 2013; 73:3749-3760.

25. Jin YH, Yoo KJ, Lee YH, Lee SK. Caspase 3-mediated cleavage of p21WAF1/CIP1 associated with the cyclin A-cyclin-dependent kinase 2 complex is a prerequisite for apoptosis in SK-HEP-1 cells. The Journal of biological chemistry. 2000; 275:30256-30263.

26. Rebbaa A, Zheng X, Chu F, Mirkin BL. The role of histone acetylation versus DNA damage in drug-induced senescence and apoptosis. Cell Death Differ. 2006; 13:1960-1967.

27. Kwong J, Hong L, Liao R, Deng Q, Han J, Sun P. p38alpha and p38gamma mediate oncogenic ras-induced senescence through differential mechanisms. The Journal of biological chemistry. 2009; 284:11237-11246.

28. Kumar S, Jiang MS, Adams JL, Lee JC. Pyridinylimidazole compound SB 203580 inhibits the activity but not the activation of p38 mitogen-activated protein kinase. Biochemical and biophysical research communications. 1999; 263:825-831.

29. Reed SM, Hagen J, Tompkins VS, Thies K, Quelle FW, Quelle DE. Nuclear interactor of ARF and Mdm2 regulates multiple pathways to activate p53. Cell cycle. 2014; 13:1288-1298.

30. Espinosa JM, Emerson BM. Transcriptional regulation by p53 through intrinsic DNA/chromatin binding and sitedirected cofactor recruitment. Molecular cell. 2001; 8:57-69.

31. Avitzour M, Diskin R, Raboy B, Askari N, Engelberg D, Livnah O. Intrinsically active variants of all human p38 isoforms. FEBS J. 2007; 274:963-975.

32. Sun Y, Jiang X, Chen S, Fernandes N, Price BD. A role for the Tip60 histone acetyltransferase in the acetylation and activation of ATM. Proceedings of the National Academy of Sciences of the United States of America. 2005; 102:13182-13187.
33. Dent P, Yacoub A, Fisher PB, Hagan MP, Grant S. MAPK pathways in radiation responses. Oncogene. 2003; 22: 5885-5896.

34. Kang YJ, Zhou ZX, Wang GW, Buridi A, Klein JB. Suppression by metallothionein of doxorubicin-induced cardiomyocyte apoptosis through inhibition of p38 mitogen-activated protein kinases. The Journal of biological chemistry. 2000; 275:13690-13698.

35. Ventura JJ, Tenbaum S, Perdiguero E, Huth M, Guerra C, Barbacid M, Pasparakis M, Nebreda AR. p38alpha MAP kinase is essential in lung stem and progenitor cell proliferation and differentiation. Nat Genet. 2007; 39:750-758.

36. Hui L, Bakiri L, Mairhorfer A, Schweifer N, Haslinger C, Kenner L, Komnenovic V, Scheuch H, Beug H, Wagner EF. p38alpha suppresses normal and cancer cell proliferation by antagonizing the JNK-c-Jun pathway. Nat Genet. 2007; 39:741-749.

37. Bulavin DV, Saito S, Hollander MC, Sakaguchi K, Anderson CW, Appella E, Fornace AJ Jr. Phosphorylation of human p53 by p38 kinase coordinates $\mathrm{N}$-terminal phosphorylation and apoptosis in response to UV radiation. The EMBO journal. 1999; 18:6845-6854.

38. Lafarga V, Cuadrado A, Lopez de Silanes I, Bengoechea R, Fernandez-Capetillo O, Nebreda AR. p38 Mitogen-activated protein kinase- and HuR-dependent stabilization of p21(Cip1) mRNA mediates the $G(1) / S$ checkpoint. Molecular and cellular biology. 2009; 29:4341-4351.

39. Wang X, McGowan CH, Zhao M, He L, Downey JS, Fearns C, Wang Y, Huang S, Han J. Involvement of the MKK6-p38gamma cascade in gamma-radiation-induced cell cycle arrest. Molecular and cellular biology. 2000; 20:4543-4552.

40. Sun P, Yoshizuka N, New L, Moser BA, Li Y, Liao R, Xie C, Chen J, Deng Q, Yamout M, Dong MQ, Frangou CG, Yates JR 3rd, Wright PE, Han J. PRAK is essential for ras-induced senescence and tumor suppression. Cell. 2007; 128:295-308.

41. Kwong J, Chen M, Lv D, Luo N, Su W, Xiang R, Sun P. Induction of p38delta expression plays an essential role in oncogenic ras-induced senescence. Molecular and cellular biology. 2013; 33:3780-3794.

42. Hong L, Lai M, Chen M, Xie C, Liao R, Kang YJ, Xiao C, Hu WY, Han J, Sun P. The miR-17-92 cluster of microRNAs confers tumorigenicity by inhibiting oncogeneinduced senescence. Cancer research. 2010; 70:8547-8557.

43. Yoshizuka N, Lai M, Liao R, Cook R, Xiao C, Han J, Sun P. PRAK suppresses oncogenic ras-induced hematopoietic cancer development by antagonizing the JNK pathway. Molecular cancer research : MCR. 2012; 10:810-820.

44. Mukhopadhyay A, Deplancke B, Walhout AJ, Tissenbaum HA. Chromatin immunoprecipitation (ChIP) coupled to detection by quantitative real-time PCR to study transcription factor binding to DNA in Caenorhabditis elegans. Nat Protoc. 2008; 3:698-709. 